Review Article

\title{
Aflatoxins in Uganda: An Encyclopedic Review of the Etiology, Epidemiology, Detection, Quantification, Exposure Assessment, Reduction, and Control
}

\author{
Timothy Omara $\mathbb{D}^{1,2,3}$ Winfred Nassazi ${ }^{10},{ }^{1,3}$ Tom Omute, ${ }^{4}$ Aburu Awath, ${ }^{5,6}$ \\ Fortunate Laker, ${ }^{3,7}$ Raymond Kalukusu, ${ }^{3,7}$ Bashir Musau (iD, ${ }^{3,7}$ \\ Brenda Victoria Nakabuye ${ }^{D},{ }^{7,8}$ Sarah Kagoya ${ }^{(D)},{ }^{3,9}$ George Otim, ${ }^{3}$ and Eddie Adupa ${ }^{3,10}$ \\ ${ }^{1}$ Department of Chemistry and Biochemistry, School of Biological and Physical Sciences, Moi University, Uasin Gishu County, \\ Kesses, P.O. Box 3900-30100, Academic Highway, Eldoret, Kenya \\ ${ }^{2}$ Department of Quality Control and Quality Assurance, Product Development Directory, AgroWays Uganda Limited, \\ Plot 34-60 Kyabazinga Way, P.O. Box 1924, Jinja, Uganda \\ ${ }^{3}$ Department of Chemistry, Faculty of Science, Kyambogo University, P.O. Box 1, Kampala, Uganda \\ ${ }^{4}$ Department of Biochemistry, Faculty of Health Sciences, Lira University, P.O. Box 1035, Lira, Uganda \\ ${ }^{5}$ Standards Department, Uganda National Bureau of Standards, Plot 2-12 Bypass Link, \\ Bweyogerere Industrial and Business Park, P.O. Box 6329, Kampala, Uganda \\ ${ }^{6}$ Department of Food Technology and Nutrition, School of Food Technology, Nutrition and Bioengineering, \\ College of Agricultural and Environmental Sciences, Makerere University, P.O. Box 7062, Kampala, Uganda \\ ${ }^{7}$ Department of Quality Control and Quality Assurance, Leading Distillers Uganda Limited, Plot 3382/83, Buloba, \\ P.O. Box 12369, Kampala, Uganda \\ ${ }^{8}$ Department of Food Processing Technology, Faculty of Science, Kyambogo University, P.O. Box 1, Kampala, Uganda \\ ${ }^{9}$ Department of Quality Control and Quality Assurance, Product Development Directory, Sweets and Confectionaries Section, \\ Kakira Sugar Limited, Jinja-Iganga Highway, P.O. Box 121, Jinja, Uganda \\ ${ }^{10}$ Department of Quality Control and Quality Assurance, Abacus Parenteral Drugs Limited, Block 191, Plot 114, Kinga, Mukono, \\ P.O. Box 31376, Kampala, Uganda
}

Correspondence should be addressed to Timothy Omara; prof.timo2018@gmail.com

Received 14 September 2019; Revised 1 November 2019; Accepted 2 December 2019; Published 8 January 2020

Academic Editor: Giuseppe Comi

Copyright (c) 2020 Timothy Omara et al. This is an open access article distributed under the Creative Commons Attribution License, which permits unrestricted use, distribution, and reproduction in any medium, provided the original work is properly cited.

Uganda is an agrarian country where farming employs more than $60 \%$ of the population. Aflatoxins remain a scourge in the country, unprecedentedly reducing the nutritional and economic value of agricultural foods. This review was sought to synthetize the country's major findings in relation to the mycotoxins' etiology, epidemiology, detection, quantification, exposure assessment, control, and reduction in different matrices. Electronic results indicate that aflatoxins in Uganda are produced by Aspergillus flavus and A. parasiticus and have been reported in maize, sorghum, sesame, beans, sunflower, millet, peanuts, and cassava. The causes and proliferation of aflatoxigenic contamination of Ugandan foods have been largely due to poor pre-, peri-, and postharvest activities, poor government legislation, lack of awareness, and low levels of education among farmers, entrepreneurs, and consumers on this plague. Little diet diversity has exacerbated the risk of exposure to aflatoxins in Uganda because most of the staple foods are aflatoxin-prone. On the detection and control, these are still marginal, though some devoted scholars have devised and validated a sensitive portable device for on-site aflatoxin detection in maize and shown that starter cultures used for making some cereal-based beverages have the potential to bind aflatoxins. More efforts should be geared towards awareness creation and vaccination against hepatitis $\mathrm{B}$ and hepatitis $\mathrm{A}$ to reduce the risk of development of liver cancer among the populace. 


\section{Introduction}

1.1. Brief Historical Perspective. Aflatoxin (AF) is a portmanteau combining "a" for the Aspergillus genus, "fla" for the species flavus, and toxin for poison [1-3]. The discovery of aflatoxins traces back to 1960 in which a severe outbreak of Turkey "X" disease was recorded in England with more than 100,000 turkeys, 20,000 ducklings, pheasants, chicks, and partridge poults reported to have died from the calamitous incident [4]. The cause was reported to be due to a series of fluorescent compounds in a peanut meal imported from South America (Brazil) that was served to the poults [5]. Later, the disease syndrome was reported in domesticated animals outside Great Britain. The causative mold, Aspergillus flavus, was finally isolated from a meal later related to a hepatic problem in ducklings in Uganda [6]. The early history of the Turkey " $X$ " disease outbreak in Great Britain was described in sufficient details by Blount [4, 7], and the toxicity recorded in various animal species was recapitulated by Allcroft [8].

1.2. Structure and Properties of Aflatoxins. Aflatoxins are highly oxygenated polysubstituted coumarins with structures that differ only very slightly. At least 18 different types of AFs have been chemically characterized (Table 1), with the six major ones being aflatoxin $B_{1}\left(A F B_{1}\right)$, aflatoxin $\mathrm{B}_{2}\left(\mathrm{AFB}_{2}\right)$, aflatoxin $\mathrm{G}_{1}\left(\mathrm{AFG}_{1}\right)$, aflatoxin $\mathrm{G}_{2}\left(\mathrm{AFG}_{2}\right)$ [11], aflatoxin $\mathrm{M}_{1}\left(\mathrm{AFM}_{1}\right)$, and aflatoxin $\mathrm{M}_{2}$ (AFM2) (Table 1). The B-aflatoxins, typically pentanone derivatives, exhibit strong blue fluorescence under ultraviolet light while the G-series (six-membered lactones) fluoresce yellow-green on thin-layer chromatography plates, thus the B and $G$ designations $[12,13]$. $\mathrm{AFB}_{2}$ and $\mathrm{AFG}_{2}$ are dihydroxy derivatives of $A F B_{1}$ and $A F G_{1}$, and the other $A F s$ are not usually reported in the absence of $\mathrm{AFB}_{1}$ [14]. The $M$ series are toxic metabolic derivatives of the $\mathrm{B}$ series that exhibit blue-violet fluorescence and have been reported in the milk of animals fed with AF-contaminated feed $[15,16]$, hence the designation $M[9,12,17-19]$. The subscripts 1 and 2 in AF nomenclature are designations for major and minor, respectively. The minor AFs have received description as mammalian biotransformation products of the major metabolites [20].

Aflatoxins are produced mainly by Aspergillus flavus, $A$. parasiticus, A. nomius, and A. tamarii [21-24] which are universally soilborne fungi responsible for decomposition of plant materials. About 20 Aspergillus species have been reported to produce AFs [25], though the exploration of more novel and potential aflatoxigenic fungi continues [26-31]. Most species produce B-type AFs via the polyketide pathway as difuranocoumarin derivatives although species related to $A$. parasiticus, $A$. nomius, $A$. toxicarius, $A$. bombycis, $A$. parvisclerotigenus, $A$. minisclerotigenes, and $A$. arachidicola are able to additionally produce G-type aflatoxins [32]. $\mathrm{AFM}_{1}, \mathrm{AFM}_{2}, \mathrm{AFB}_{2 \mathrm{~A}}$, and $\mathrm{AFG}_{2 \mathrm{~A}}$ have been isolated from cultures of $A$. flavus and $A$. parasiticus while
$\mathrm{AFGM}_{1}$, parasiticol, and aflatoxicol are solely produced by A. flavus [16].

Chemically, AFs are unique highly substituted coumarins containing a fused dihydrofurofuran moiety [33]. The B-series are characterized by fusion of a cyclopentenone ring to the lactone ring of the coumarin moiety whereas the G-series contain a fused lactone ring [34]. $\mathrm{AFB}_{1}$ and $\mathrm{AFG}_{1}$ possess an unsaturated bond at the 8, 9 position on the terminal furan ring, and some studies illustrated that oxiranation at this chemical position is pivotal for their toxicological potency. $\mathrm{AFB}_{2}$ and $\mathrm{AFG}_{2}$ are comparatively less toxic, unless they are first oxidized to $\mathrm{AFB}_{1}$ and $\mathrm{AFG}_{1}$ in vivo [33]. AFs are soluble in polar protic solvents [15].

1.3. Toxicological Properties of Aflatoxins. In kingdom Animalia, AFs are reported to be multiplicatively carcinogenic, genotoxic, tremorgenic, haemorrhagic, dermatitic, mutagenic, teratogenic, and immunosuppressive [11]. They display potency of toxicity, carcinogenicity, and mutagenicity in the order: $\mathrm{AFB}_{1}>\mathrm{AFM}_{1}>\mathrm{AFG}_{1}>\mathrm{AFB}_{2}>\mathrm{AFM}_{2}>$ $\mathrm{AFG}_{2}$ as exemplified by their lethal dose that causes the death of $50 \%$ of subjects ( $\mathrm{LD}_{50}$ values) being $0.1-50 \mathrm{mg} / \mathrm{kg}$ body weight for most animal species and $<1.0 \mathrm{mg} / \mathrm{kg}$ body weight for susceptible species [35-37] (Table 2). The order also reflects the role played by the epoxidation of the 8,9 double bond and the greater potency associated with the cyclopentenone ring of the B-series. Trial tests on animal species and mammalian cells have unveiled toxicities of $\mathrm{AFG}_{1}, \mathrm{AFB}_{2}$, and $\mathrm{AFG}_{2}$ as approximately $50 \%, 20 \%$, and $10 \%$ that of $\mathrm{AFB}_{1}$ [38]. Susceptibility though varies with breed, species, age, dose, length of exposure, and nutritional status of the exposed animals (Table 2).

$\mathrm{AFB}_{1}$ is listed as a human class 1 carcinogen $[40,41]$ and the most potent carcinogen known $[42,43]$ that may play a part in the etiology of human liver cancer. This is due to its demonstrated ability to bind to nucleic acids (DNA and RNA) and proteins [40, 44, 45]. The carcinogenicity of AFs has been shown to operate by a genotoxic mechanism involving metabolic activation to a genotoxic epoxide metabolite, formation of DNA adducts, and modification of the TP53 gene which involves the transversion of guanosine to thymine [43]. AFs interact with basic metabolic pathways of the cell, disrupting key enzyme processes including carbohydrate and lipid metabolism as well as protein synthesis. It is unfortunately reported that where $A F s$ are detected in foods, $A_{F}$ usually exceeds half the total amount present, explaining the reason why compliance limits for AFs include $\mathrm{AFB}_{1}$ and several analytical methods have been developed and validated to quantify its concentration in foods [46]. Aflatoxin $\mathrm{M}_{1}$, like $\mathrm{AFB}_{1}$, is a classified group $2 \mathrm{~B}$ probable human carcinogen [47].

Human exposure to AFs has documented deleterious health effects including acute aflatoxicosis and chronic exposure leading to liver cancer with 8.19 cases reported per 100,000 inhabitants in Africa annually [40]. About 3,700 of 
TABLE 1: Types and chemical structure of common aflatoxins.

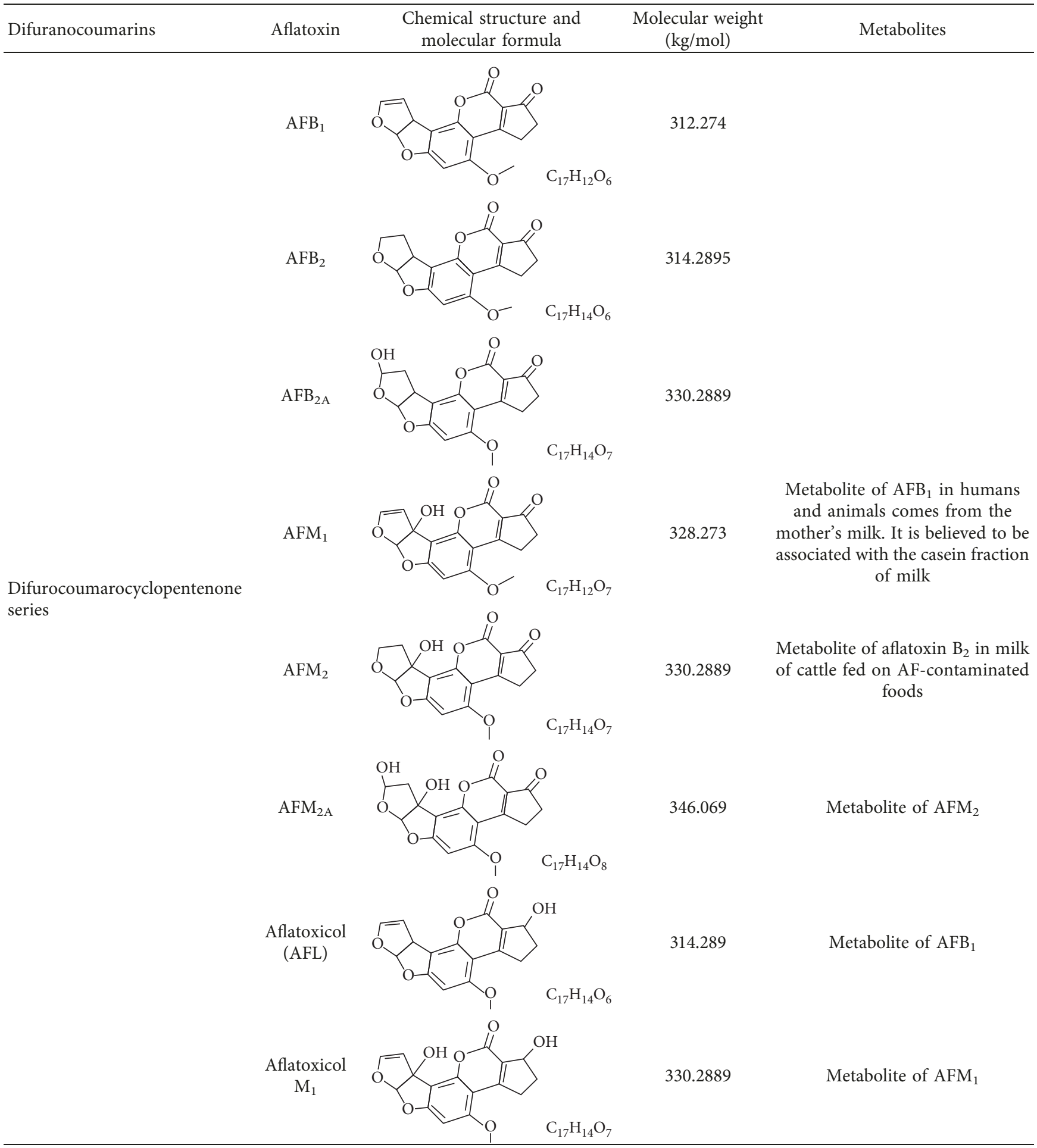


TABle 1: Continued.

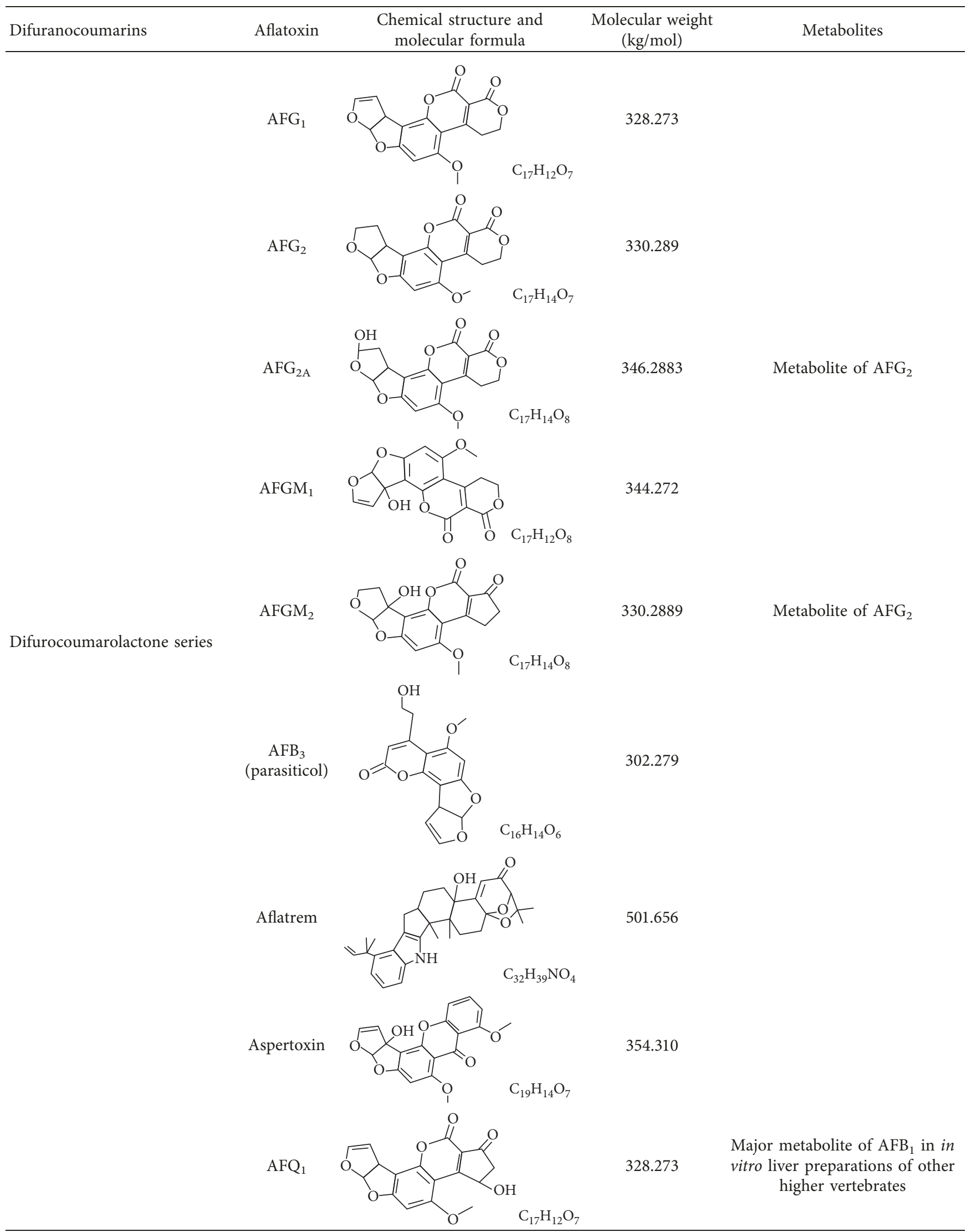

Source: modified after $[9,10]$. 
TABLe 2: Median lethal dose for $\mathrm{AFB}_{1}$ administered as a single dose to different animals.

\begin{tabular}{lccc}
\hline Animal & Sex & Age/size & LD $_{50}(\mathrm{mg} / \mathrm{kg}$ body weight $)$ \\
\hline Golden hamster & Male & 30 days & 10.2 \\
Rat & Male/female & 1 day & 1.0 \\
Rat & Male & 21 days & 5.5 \\
Rat & Female & 21 days & 7.4 \\
Rat & Male & $0.001 \mathrm{~kg}$ & 17.5 \\
Dog & Male/female & Adult & 0.5 \\
Pig & Unspecified & $6-7 \mathrm{~kg}$ & 0.6 \\
Chicken embryo & Unknown & Not applicable & 0.025 \\
Duckling & Male & 1 day & 0.37 \\
\hline
\end{tabular}

Source: Agag [38], Ciegler [10], and Robens and Richard [39]. $1 \mathrm{mg} / \mathrm{kg}=1000 \mu \mathrm{g} / \mathrm{kg}$.

these cancer cases are from Uganda [41]. In fact, the risk of developing liver cancer is reported to be high (50\% more) in cases where the individuals are carriers of hepatitis $\mathrm{B}$ and hepatitis C surface antigens [42]. In addition, AFs impair protein synthesis and induce coagulation, weight gain, and immunogenesis [39].

Food-borne AFs have been implicated for inducing infantile stunting $[43,44]$ probably by interfering with protein synthesis and the activity of micronutrients (vitamins: $A, B_{12}, C, D$, and $E$, zinc, selenium, iron, and calcium) [16]. Diminished feeding and weight loss have been reported in domesticated animals fed on AF-contaminated feed [43], ensued by death. AFs also cause lower milk and egg production as well as immune suppression due to the reaction of AF with T cells (perforin, perforin-expressing, and granzyme A-expressing $\mathrm{CD}^{+}$T cells) [45] and a decrease in vitamin $\mathrm{K}$ activities [39].

All these have economic impacts, extensible to the national economy, estimated at 128 billion annually for Uganda [46]. In 2013, more than 600,000 tons of maize worth Uganda shillings 10 billion destined for export to neighbouring Kenya was rejected because they had AFs above regulatory limits [47].

\section{Etiology of Aflatoxins in Uganda and the Commodities Contaminated}

2.1. Etiology. In Uganda, AFs are produced predominantly by A. flavus and A. parasiticus [48]. A. flavus is ubiquitous and is reported to produce $\mathrm{AFB}_{1}$ and $\mathrm{AFB}_{2}$ along with other mycotoxins: cyclopiazonic, kojic, and aspergillic acids [32]. A. parasiticus produces $\mathrm{AFB}_{1}, \mathrm{AFB}_{2}, \mathrm{AFG}_{1}$, and $\mathrm{AFG}_{2}$ accompanied by mycotoxic kojic and aspergillic acids $[32,49,50]$.

The climatic conditions in Uganda such as heavy rains, sudden droughts, high humidity, average temperature of $25^{\circ} \mathrm{C}$, occasional floods as well as poor pre-, peri, and postharvest handling of foods by farmers and traders in the food value chain have been implicated for the proliferation of AFs in Ugandan foods [48].

Biophysical factors such as soil (substrate composition), crop species (host-plant susceptibility and genotype), and fungal populations (strain specificity and variation, instability of toxigenic properties) as well as levels of education, awareness, and gender are another probable set of factors contributing to AF contamination and prevalence in agricultural foods in Uganda as reported elsewhere [51, 52]. Other factors that may influence AF production include water activity, $\mathrm{pH}$, surrounding concentration of oxygen and carbon dioxide, microbial competition, mold lineage, plant stress, and use of fungicides or fertilizers.

A. flavus and A. parasiticus are semithermophilic and semixerophytic, thriving favorably between $12^{\circ} \mathrm{C}$ and $48^{\circ} \mathrm{C}$ and at lower water potentials [53]. Optimum growth occurs between $25^{\circ} \mathrm{C}$ and $42^{\circ} \mathrm{C}$ and low water activity associated with droughts as in Uganda. These factors contribute to the epidemiology of the two Aspergillus fungi. Despite the optimum temperature for $\mathrm{AF}$ biosynthesis reported to be between $28^{\circ} \mathrm{C}$ and $35^{\circ} \mathrm{C}$, some studies indicate higher temperatures inhibit AF biosynthesis [54, 55]. Thus, the conditions in Uganda favor A. flavus and A. parasiticus growth along with their aflatoxigenic contamination of foods.

In Uganda, $\mathrm{AFB}_{1}$ is the most studied [56] while $\mathrm{AFM}_{1}$ has received little attention [57]. Thus, most studies reported $\mathrm{AFB}_{1}$ levels or did not distinguish between the different types [58-63]. Others, such as the validation survey of Wacoo et al. [64], Muzoora et al. [65], Baluka et al. [66], and Wacoo et al. [67], differentiated the AFs. By and large, the lack of this depth in most studies can be tailored to the overall priority of simply analyzing the safety of foods and/or individuals. More so, there was a limited facility to handle $\mathrm{AF}$ analysis as well as lack of funds to procure the analytical grade reagents [48]. Despite the documented differences in toxicity, all AFs are harmful and should be detected, quantified, and rigorously controlled. Further, there is a dire need for comprehensive and coherent data on potential mycotoxins [68].

2.2. Commodities Contaminated. Aflatoxigenic contamination in Uganda has been reported in maize (Zea mays L.) $[59,62,63,69]$, sorghum (Sorghum bicolor L.), finger millet (Eleusine coracana) and their local products [58], peanuts (Arachis hypogaea L.) [57, 65, 66, 70], cassava (Manihot esculenta) [71], rice (Oryza sativa) [72], sunflower (Helianthus annuus), sesame (Sesamum indicum L.) [63], animal feeds [73], and a bovine milk-based product [57]. AFs have also been detected in human sera $[60,61,74]$. Virtually all grains, spices, and other oil seeds cannot be exempted [47]. 
2.2.1. Peanuts (Arachis hypogaea L.). Peanuts (groundnuts) are the only cheap source of plant proteins, second in importance to beans and majorly cultivated in Eastern and Northern Uganda but consumed countrywide [75]. It is consumed as seeds, raw, roasted, blanched, peanut butter, or mixed with traditional dishes as a sauce or as ebinyewa (paste or flour) [76].

Lopez and Crawford [70] reported on the AF content of peanuts sold for human consumption in Uganda. On average, $15 \%$ of the samples had more than $1.0 \mu \mathrm{g} / \mathrm{kg}$ of $\mathrm{AFB}_{1}$ while $2.5 \%$ contained more than $10 \mu \mathrm{g} / \mathrm{kg}$ of $\mathrm{AFB}_{1}$. The contamination levels were at peak at the end of the rainy season prior to the new harvest season. Further, Korobkin and Williams [77] reported the need for AF analysis of peanuts consumed by the community of West Nile as investigation of primary liver carcinoma and groundnut growing regions of Arua showed some correlation between cancer cases reported in the tumor registry of Kuluva Hospital (between 1951 and 1965) to the distribution of the peanut growing areas.

Total AFs were reported in $80 \%$ of peanut and peanut paste samples traded in metropolitan Kampala with $40 \%$ of these having AF content exceeding FDA/WHO compliance limit of $20 \mu \mathrm{g} / \mathrm{kg}$ by Osuret et al. [78]. Unprecedented AF levels $(940 \mu \mathrm{g} / \mathrm{kg}$ and $720 \mu \mathrm{g} / \mathrm{kg})$ were reported in peanut paste and peanut seeds, respectively.

The aforeacknowledged studies never correlated the AF contaminations with their causes. Subsequently, Kaaya et al. [79] reported in a correlative study that at farm level in villages, up to $60 \%$ of peanuts had detectable AFs (Table 3 ). Further, low levels of awareness, poor storage practices, and poor processing practices (drying, sorting, and milling) were implicated for the heightened AF levels registered, stressing that aflatoxigenic contamination commences right from farms. Comparative analysis of market peanuts unveiled significantly higher total AF contents in retailed samples than those wholesaled.

In a similar concerted study [57], up to $100 \%$ of peanut flour samples used in Southwestern Uganda culinary recipes were reported positive for total AFs with a mean of $11.5 \pm 0.43 \mu \mathrm{g} / \mathrm{kg}$ (Table 4 ). Lack of awareness and knowledge of AF contamination control were reported to be the probable reasons for the high AF levels recorded.

Muzoora et al. [65] screened 120 peanut samples sourced from Ugandan districts of Kampala, Mubende, Gulu, Pader, Mbarara, Masindi, and Kaberamaido for AFs followed by competitive enzyme-linked immunosorbent assay (ELISA) quantification. Their report indicated that $72 \%$ of the samples were $A F-$ positive with $26 \%$ having $\mathrm{AFB}_{1}, \mathrm{AFB}_{2}$, $\mathrm{AFG}_{1}$, and $\mathrm{AFG}_{2}$ whereas $\mathrm{AFB}_{1}$ and $\mathrm{AFG}_{1}$ containing samples constituted $74 \%$ of the total samples. More urban samples (67.1\%) were AF-positive than rural samples (47.6\%). ELISA gave $81 \%$ AF-positive samples, with milled groundnuts registering higher total AF (range: 0.31 to $1,1732 \mu \mathrm{g} / \mathrm{kg}$; mean: $1,277.5 \pm 382.2 \mu \mathrm{g} / \mathrm{kg}$ ) compared to whole groundnut seeds (range: 1.6 to $516 \mu \mathrm{g} / \mathrm{kg}$; mean: $84.7 \pm 43.8 \mu \mathrm{g} / \mathrm{kg}$ ). Up to $52 \%$ of the samples in the study registered total AF contents greater than the FDA/WHO maximum compliance limit of $20 \mu \mathrm{g} / \mathrm{kg}$ for total $\mathrm{AF}$ in peanuts. There were typically no significant differences reported in the AF content of peanuts from the different regions. The study implicated milling of fungal contaminated peanuts by traders to shield evidence of spoilage from consumers and the skewed distribution of AF in the studied matrices for the reported relative differences in AF levels of milled and whole peanuts.

Partnership for Aflatoxin Control in Africa (PACA) report [80] indicates that peanuts in Uganda are mycotoxicologically unfit for human consumption. Kioga plains (Iganga and Soroti districts) in a survey had 20\% of the peanuts with AF levels above $10 \mu \mathrm{g} / \mathrm{kg}$ while Tororo had $10 \%$ of the samples above the regulatory limit of $10 \mu \mathrm{g} / \mathrm{kg}$. In addition, other agroecological zones had $10 \%$ of peanut samples with AF contamination in levels above $10 \mu \mathrm{g} / \mathrm{kg}$ except for Northeastern which had none of the samples with detectable AFs. The report is substantiated by investigations of Baluka et al. [66] which reported that $34 \%$ of 55 peanut samples analyzed in a study contained AFs in concentrations greater than the East African and FDA/WHO compliance limits for AFs in peanuts.

From the foregoing reports, it can be noted that very high concentrations of AFs have been reported in peanuts in Uganda. This could be because as the pods grow in the soil, various aflatoxigenic fungi contaminate the shells, testa, and seeds. Worse still, mechanical damage during harvest, drying, and storage further increases the chances of fungal contamination and mycotoxin production. This is substantiated by a study which revealed that grains and oilseeds from maize, sorghum, and sunflower produced in above the ground reproductive structures had relatively lower AF contamination compared to those produced in geocarpic structures of groundnut and Bambara nut [81].

2.2.2. Cereals (Maize, Millet, Sorghum, and Rice) and Cereal-Based Products. The occurrence of mycotoxins and associated aflatoxigenic $A$. flavus/A. parasiticus in staple Ugandan foods and their derivative poultry feeds were evaluated by Sebunya and Yourtee [73]. The fifty-four (54) samples of maize, peanuts, soybean, and poultry feed samples taken and precultured on A. flavus/parasiticus selective agar (AFPA) were analyzed for their fungal content on a coconut agar medium under ultraviolet light with a subsequent confirmatory scrutinization for AF production in a pure culture. Twenty-five (25) of the samples were analyzed for $\mathrm{AFB}_{1}, \mathrm{AFG}_{1}$, zearalenone, sterigmatocystin, ochratoxin A, citrinin, vomitoxin, and diacetoxyscirpenol. A. flavus/parasiticus were reported in $77 \%$ of maize and peanuts (36\% human food; $83.3 \%$ animal feed) and $66.6 \%$ in poultry feed. No fungus was detected in soybeans whereas two $(8 \%)$ of the 25 mycotoxin-scrutinized samples had $20.0 \mu \mathrm{g} / \mathrm{kg}$ of $\mathrm{AFB}_{1}$ (4 times the statutory limit of $5.0 \mu \mathrm{g} / \mathrm{kg}$ for $\mathrm{AFB}_{1}$ in Ugandan foods).

Five baby food products locally produced in Uganda were bought from different shops and supermarkets at the stage of consumption and investigated for contamination by different toxigenic fungi and AFs by Ismail et al. [80]. These foods, each with one or more cereal flour as an ingredient, 
TABLE 3: Aflatoxin content of peanuts from farmers in some selected peanut growing districts of Uganda.

\begin{tabular}{lcccc}
\hline \multirow{2}{*}{ Village (district) } & \multirow{2}{*}{ Samples analyzed } & \multicolumn{2}{c}{ Aflatoxin status } & \multirow{2}{*}{ Aflatoxin concentration $(\mu \mathrm{g} / \mathrm{kg})$} \\
\hline Kabulamuliro (Mubende) & $n=25$ & 80 & Negative $(\%)$ & $12.4 \pm 5.31$ \\
Kiboyo (Iganga) & $n=20$ & 75 & 15 & $10.5 \pm 6.15$ \\
Bugodi (Mayuge) & $n=15$ & 60 & 40 & $7.3 \pm 4.98$ \\
Gayaza (Mubende) & $n=12$ & 67 & 33 & $9.8 \pm 4.32$ \\
\hline
\end{tabular}

Adapted from Kaaya et al. [79].

TABle 4: Total AF content of some selected foods in some Ankole districts of Southwestern Uganda.

\begin{tabular}{|c|c|c|c|c|}
\hline \multirow{2}{*}{ Matrix/food sample } & \multirow{2}{*}{ Samples analyzed } & \multicolumn{2}{|c|}{$\%$ AF-positive samples } & \multirow{2}{*}{ Average total AF $(\mu \mathrm{g} / \mathrm{kg})$} \\
\hline & & $<4.0 \mu \mathrm{g} / \mathrm{kg}(\%)$ & $>4.0 \mu \mathrm{g} / \mathrm{kg}(\%)$ & \\
\hline Peanut flour & $n=3$ & 0 & 100 & $11.5 \pm 0.43$ \\
\hline Sorghum (flour and porridge) & $n=7$ and $n=15$ & 42. 9 and 13.3 & 57.1 and 86.7 & $15.2 \pm 0.20$ \\
\hline Millet (flour and porridge) & $n=12$ and $n=21$ & 25 and 0 & 75 and 100 & $14.0 \pm 1.22$ \\
\hline Cassava flour & $n=18$ & 38.9 & 61.1 & $16.0 \pm 1.66$ \\
\hline Eshabwe (porridge) sauce & $n=14$ & 7.1 & 92.9 & $18.6 \pm 2.40$ \\
\hline
\end{tabular}

Excerpted from Kitya et al. [57].

were cultured using the dilution plate method and three selective isolation media (pentachloronitrobenzene rose Bengal yeast extract sucrose agar (PRYES), peptone-pentachloronitrobenzene agar (peptone-PCNB), and AFPA) and enumerated. PRYES plates revealed a high level of contamination of the foods by Penicillium, with three species being nephrotoxigenic ( $P$. viridicatum, $P$. verrucosum, and $P$. citrinum). On the one hand, nine species of Fusarium were recovered in high frequencies and counts on peptonePCNB. Of these, F. verticillioides followed by F. solani were the most prevalent while $F$. proliferatum and F. tricinctum had more propagules. In addition, aflatoxigenic Aspergilli were isolated on AFPA from the majority of samples of all the products investigated. A. flavus, A. niger, Cladosporium, and yeasts were prevalent. Regarding total AFs, all samples analyzed were contaminated, though the levels detected were below or in the current tolerance level of $10 \mu \mathrm{g} / \mathrm{kg}$ and $20 \mu \mathrm{g} /$ $\mathrm{kg}$ accepted in foodstuffs by Ugandan standards and WHO/ FDA, respectively. The contaminated foods constitute a health hazard to babies as they have a more restricted diet and generally consume more food on a body weight basis than adults. They concluded that the foods must be examined regularly to assess their quality.

Lee et al. [69] reported that $11 \%$ of 55 maize samples collected in a survey were contaminated with AF in the range of $12.7-123.5 \mathrm{mg} / \mathrm{kg}$, $9 \%$ of which exceeded the maximum regulatory limit. PACA [78] reported that sorghum from the different agroecological zones represented by Lira, Gulu, Amuria, Soroti, and Tororo districts of Uganda recorded between 90 and $100 \%$ of the samples positive for AFs, with total AFs ranging from 4.0 to $265.5 \mu \mathrm{g} / \mathrm{kg}$ (mean from 11.5 to $170.1 \mu \mathrm{g} / \mathrm{kg}$ ). Between $85 \%$ and $100 \%$ of the samples registered total AF greater than $4 \mu \mathrm{g} / \mathrm{kg}$, while between $70 \%$ and $100 \%$ of the samples had AF greater than $10 \mu \mathrm{g} / \mathrm{kg}$. Between $65 \%$ and $100 \%$ of the samples had AF content greater than $20 \mu \mathrm{g} / \mathrm{kg}$. Kitya et al. [57] further reported that millet and sorghum from Southwestern Uganda had mean total AF contents of $14.0 \pm 1.22 \mu \mathrm{g} / \mathrm{kg}$ and $15.2 \pm 0.2 \mu \mathrm{g} / \mathrm{kg}$, respectively (Table 4). A regional report cited in [82] indicates that maize in Uganda is the least contaminated in the East African Community (Table 5).

The moisture and total aflatoxin content of 27 samples of fresh harvested maize from Mubende, Ibanda, Jinja, Mayuge, Buikwe, Hoima, Mpigi, Masindi, and Bugiri districts of Uganda representing the agroecological zones: Lake Victoria crescent, Western Highlands, South East, and Lake Albert crescent were determined by Omara [65]. The moisture content ranged from $12.9 \%$ to $18.8 \%$ (mean: $13.9 \pm 0.35 \%$ to $17.2 \pm 1.55 \%)$ with the highest moisture recorded in maize from Ibanda. The highest mean AF content of $11.0 \pm 3.01 \mu \mathrm{g} /$ $\mathrm{kg}$ was recorded in maize from Hoima while the lowest AF content of $3.8 \pm 1.30 \mu \mathrm{g} / \mathrm{kg}$ was reported in maize from Mpigi. All the samples had detectable AFs, but none had AF content greater than $20 \mu \mathrm{g} / \mathrm{kg}$. The lower levels of aflatoxin recorded in this study were attributed to the fact that the maize had not undergone postharvest handling practices which are reported to increase AF content in maize [58]. The study concluded that maize in Uganda is precontaminated by AFs prior to harvest and recommended that farmers should plant maize varieties with established maturity periods to ensure timely harvesting.

2.2.3. Cassava (Manihot esculenta L.). Cassava is one of the most important staple foods in Uganda grown majorly in Northern Uganda and Eastern Uganda [81]. The dynamics in cyanogen levels during the processing, the associated microflora, proteinaceous content, amino acid patterns, and mycotoxin contamination of cassava products processed traditionally by the Alur people of West Nile were investigated by Essers et al. [83]. Cassava tuber processing was monitored at six rural households and replicated in an analytical laboratory setting, comparing it to sun-drying. Cassava flours from the rural households were analyzed for residual cyanogens, mutagenicity, cytotoxicity, and AFs. No AFs were detected in the samples. 
TABLe 5: Per capita food and aflatoxin contamination patterns in the East African region.

\begin{tabular}{lccc}
\hline Food & Country & Per capita food consumption $(\mathrm{g} /$ person/day) & Mean AF content $(\mu \mathrm{g} / \mathrm{kg})$ \\
\hline \multirow{2}{*}{ Maize } & Uganda & 400 & 9.7 \\
& Tanzania & 69 & 49.7 \\
& Kenya & 405 & 131.7 \\
Groundnuts (peanuts) & Uganda & & 25.1 \\
& Tanzania & 65 & 15.0 \\
Cassava chips & Burundi & & 12.5 \\
Sorghum & Uganda & 214 & 0.5 \\
Milk & Tanzania & 40 & 0.9 \\
& Tanzania & $750 \mathrm{ml}$ & 3.0 \\
\hline
\end{tabular}

Adapted from the report by the East African Community's aflatoxin working group in April 2013 (Dar es Salaam-Tanzania, EAC/TF/405/2013) cited in a penultimate study [82].

Data available in open literature have reported AF contamination of cassava in Uganda at an average content of $0.5 \mu \mathrm{g} / \mathrm{kg}$ (Table 5). Osuret et al. [78] found 20\% (1/ 5) samples of cassava sold in metropolitan Kampala to be aflatoxigenically contaminated in levels above the $\mathrm{WHO} /$ US EPA compliance limit of $20 \mu \mathrm{g} / \mathrm{kg}$. In a similar concerted investigation, Kitya et al. [57] bewrayed that cassava chips in Southwestern Uganda are mycotoxicologically contaminated with a mean total AF content of $16.0 \pm 1.66 \mu \mathrm{g} / \mathrm{kg}$. Kaaya and Eboku [71] reported Rhizopus (66.7\%), Mucor (37\%), Penicillium (22.2\%), Aspergillus (20.4\%), and Fusarium species (5.6\%) as the fungi contaminating dry cassava chips in Eastern Uganda with up to $30 \%$ of the samples registered positive for AF (mean total AF content was $0.51 \mu \mathrm{g} / \mathrm{kg}$; AF range was 0.0 to $4.5 \mu \mathrm{g} / \mathrm{kg}$ ). A. flavus regrettably was reported in $18.5 \%$ of the analyzed samples.

2.2.4. Animal Products. Most of $\mathrm{AFB}_{1}$ and $\mathrm{AFB}_{2}$ ingested by mammals are eliminated through urine and faeces. A fraction of this is biotransformed in the liver and excreted in milk and urine as $\mathrm{AFM}_{1}$ and $\mathrm{AFM}_{2}$, respectively. $\mathrm{AFM}_{1}$ is detectable in milk 12-24 hours after the first $\mathrm{AFB}_{1}$ ingestion, reaching a high level after a few days. Thus, dietary exposure to AFs through consumption of milk from lactating animals fed on AF-contaminated feeds in Uganda is as high as microbial contamination of milk reported in Metropolitan Kampala [84]. In Western Uganda, Kitya et al. [57] reported that a bovine milk-based ghee sauce (Eshabwe) had a mean total AF content of $18.6 \pm 2.4 \mu \mathrm{g} / \mathrm{kg}$ which was the highest of all the matrices tested for AFs in the Ankole districts of Mbarara, Ntungamo, Rukungiri, Kasese, and Kabale (Table 4). Eshabwe is a traditional Ankole delicacy prepared from unprocessed ghee, rock salt, boiled cold water, and salt and is commonly prepared for special ceremonies as a condiment [85]. Given the fact that this sauce is almost prepared by every Ankole family, the study indicated that the high incidences of hepatocellular carcinoma could be correlated to the consumption of such aflatoxin-contaminated foods resulting from the traditional food processing techniques [57].

Upon ingestion of $\mathrm{AFB}_{1}$, cytochrome $\mathrm{P} 450$ enzymes (CYP) (including CYP1A2, CYP3A4, and CYP2A6) in the liver and other tissues convert $\mathrm{AFB}_{1}$ to epoxides $\left(\mathrm{AFB}_{1}\right.$ 8,9-exo-epoxide and $\mathrm{AFB}_{1}-8,9$-endo-epoxide) and to $\mathrm{AFM}_{1}, \mathrm{AFP}_{1}, \mathrm{AFQ}_{1}$, and its reduced form aflatoxicol. Of the epoxides, the $\mathrm{AFB}_{1}-8,9$-exo-epoxide can form covalent bonds with DNA and serum albumin resulting in $\mathrm{AFB}_{1}$ N7-guanine and lysine adducts, respectively. Like $\mathrm{AFB}_{1}$, $\mathrm{AFM}_{1}$ can be activated to form $\mathrm{AFM}_{1}-8,9$-epoxide that binds to DNA resulting in $\mathrm{AFM}_{1}$-N7-guanine adducts. Guanine and lysine adducts have been noted to appear in urine. The metabolites $\mathrm{AFP}_{1}, \mathrm{AFQ}_{1}$, and aflatoxicol are thought to be inactive and are excreted as such in urine, or in the form of glucuronyl conjugates from bile in faeces [86].

In Uganda, there is no report on the aflatoxin content of other products of animal origin such as meat and blood.

2.3. Co-Occurrence of Aflatoxins with Other Mycotoxins in Ugandan Foods. Several mycotoxins can occur simultaneously in matrices [87]. The statutory and regional regulations in place for food and feed products are based entirely on AFs, failing to take into consideration possible combined toxic effects of different mycotoxins. Some studies in Uganda have reported the co-occurrence of AFs with some mycotoxins. In an investigation by Sebunya and Yourtee [72] on 25 samples of foods analyzed for $\mathrm{AFB}_{1}$, $\mathrm{AFG}_{1}$, zearalenone, sterigmatocystin, ochratoxin $\mathrm{A}$, citrinin, vomitoxin and diacetoxyscirpenol, zearalenone, and vomitoxin were detected in 3 and 2 maize samples, respectively.

Following a WHO meeting on nodding syndrome in Kampala (Uganda) in 2012, it was recommended that fungal contamination of foods should be investigated as a possible cause of the disease. Echodu et al. [63] assessed the relationship between consumption of mycotoxin-contaminated foods (sorghum, millet, sunflower, groundnut, sesame, and maize) and the development of nodding syndrome in the affected Northern districts of Lamwo and Kitgum. Very high levels of total AFs and ochratoxins in millet, sorghum, maize, and groundnuts in both households with and without children with nodding syndrome were registered. No significant association between concentrations of the mycotoxins and the presence of children with nodding syndrome in households was noted. Sorghum in this study had the 
highest total AF ranging from 0.00 to $68.2 \mu \mathrm{g} / \mathrm{kg}$ while the lowest AF was recorded in sesame (maximum AF of $4.5 \mu \mathrm{g}$ / $\mathrm{kg}$ ). In this study, the highest ochratoxin and vomitoxin/ deoxynivalenol contents were $7.647 \mu \mathrm{g} / \mathrm{kg}$ and $2.606 \mu \mathrm{g} / \mathrm{kg}$ reported in sorghum and maize from Lamit Tumangu village, Kitgum district, respectively.

Baluka et al. [66] compared mycotoxins and selected trace metal content of peanuts sold in selected markets in Kampala, Uganda, to those traditionally prepared. Commercially processed peanut samples $(n=33)$ were purchased from St. Balikuddembe, Nakawa, Kalerwe, and Bukoto markets of Metropolitan Kampala whereas control samples $(n=5)$ were unground peanuts procured from the markets and processed using traditional methods or by metal grinding. Aflatoxins: $B_{1}, B_{2}, G_{1}, G_{2}$, fumonisins, deoxynivalenol, nivalenol, ochratoxin $\mathrm{A}$, T2 toxin, zearalenone, zearalenol, and heavy metals: arsenic, boron, barium, cadmium, chromium, copper, mercury, magnesium, nickel, lead, and zinc were analyzed. AF, particularly $\mathrm{AFB}_{1}$, was reported as the predominant mycotoxin in the samples. There were significantly higher concentrations of AFs in market-processed than in home-processed samples. AF concentrations were in the range of $0-540 \mu \mathrm{g} / \mathrm{kg}$ for $\mathrm{AFB}_{1}$, $0-141 \mu \mathrm{g} / \mathrm{kg}$ for $\mathrm{AFB}_{2}, 0-213 \mu \mathrm{g} / \mathrm{kg}$ for $\mathrm{AFG}_{1}, 0-36 \mu \mathrm{g} / \mathrm{kg}$ for $\mathrm{AFG}_{2}$, and $0-849 \mu \mathrm{g} / \mathrm{kg}$ for total AFs. Cadmium and lead content of the samples were below the method limit of detection of $0.25 \mathrm{ppm}$ though one sample (2.6\%) had arsenic above the FDA maximum concentration of $1.4 \mathrm{ppm}$. The concentrations of chromium and mercury in $100 \%$ of the samples were below the FDA limit of 1 and $0.5 \mathrm{ppm}$, respectively. Roasting and duration of grinding had no appreciable effect on AFs and metalliferous content of the samples. The study recommended the need for food-borne toxicant monitoring of foods traded for human consumption in Ugandan markets [66].

\subsection{Geographical Distribution of Aflatoxins in Uganda.} Brazil was the first hotspot of AFs recorded [88] before subsequent reports cited Uganda, Kenya, Senegal, Mozambique, Swaziland, Nigeria, China, Thailand, and the Philippines [89]. Sherck-Hanssen [90] reported in 1970 a case report that implicated the death of a Ugandan to be linked with ingestion of aflatoxin-contaminated cassava. The 15year-old boy was admitted to Mulago Hospital, Kampala, on June 4, 1967, with abdominal pains and swelling of the legs for a couple of days. The pulse rate was declared normal. Probing clinical analyses reported that he was having heart failure. Upon administration of digitoxin and mersalyl sodium, the boy passed away two days after admission. An autopsy recorded edema and congestion of the lungs with diffuse necrosis of the liver. Histology revealed centrilobular necrosis, and subsequent aflatoxigenic investigation of a sample of the cassava eaten by the boy with his sister and brother (who also became ill but survived) indicated the cassava had $1,700 \mu \mathrm{g} / \mathrm{kg}$ of aflatoxin $\mathrm{B}_{1}$ which is markedly lethal if ingested for over three weeks when compared with the acute toxicity dose of $220 \mu \mathrm{g} / \mathrm{kg} \mathrm{AFB} \mathrm{An}_{1}$ in African monkeys [91].
Uganda is divided into ten agroecological zones: Southern highlands, Southern dry lands, Lake Victoria crescent, Eastern, Mid-Northern, Lake Albert crescent, West Nile, Western highlands, South East, and Karamoja drylands [92]. AFs tend to be recorded at nearly equal concentrations in food samples from the different zones. This can be attributed to the similarity in the agronomic, pre-, peri-, and postharvest handling practices and the interregional marketing of foods in Uganda [80].

In one of the pioneering surveys, the AF content of 480 foods stored for consumption between harvests in Uganda between September 1966 and June 1967 was evaluated by Alpert et al. [93]. Up to $29.6 \%$ of these had detectable AF with $3.7 \%$ of the samples recording $>1.0 \mu \mathrm{g} /$ $\mathrm{kg}$ AF content. Beans had the highest AF content (72\%), while the prevalence of aflatoxins in maize, peanuts, and cassava was reported at $45 \%, 18 \%$, and $12 \%$, respectively. Rice in this study had no detectable aflatoxins. The high prevalence of aflatoxigenic contamination reportedly correlated with provinces with a high recorded hepatoma incidence or moldy food consumption (Table 6). This led to the postulation that AF exposure may be a contributing factor for the elevated levels of hepatoma in Uganda [89]. In the same study, the local cancer registry in the regions where samples were drawn was checked for the period 1964 to 1966 . The study indicated that the Karamoja region had the highest hepatoma frequency of 6.8 cases per 1,000 people per annum with a frequency of AF contamination at $44 \%$ (Table 7). Overall, hepatoma occurred at an average rate of 1.0 to 2.7 cases per 1,000 people per year [93].

No study has reported in the open literature on the AF content of beer consumed by Ugandans, yet it is among the most consumed foods that perhaps use all the major cereals: maize, sorghum, and barley as well as cassava. Beers are practically products of mixed-culture fermentations, a process that continues up to consumption time. Thus, brewing is an ideal route for exposure to AFs as it offers favorable conditions for aflatoxigenic fungal growth [90] and creates an avenue for use of contaminated grains as the final consumers will not be able to physically detect as reported for peanut paste [65].

\section{Capacity for Detection and Quantification}

Specific, sensitive, and simple analytical methods for detection and quantification of AFs are prerequisites for their accurate detection and quantization given their presence in very meagre concentrations and their skewed nature of distribution in matrices [94]. The accuracy, precision, reproducibility, and repetitiveness of analytical techniques for detection and quantification of the AF content of a commodity are largely influenced by the way each step in the analytical process from sampling to extraction, cleanup, and quantification is perfected. One of the biggest challenges is that it is often hard to obtain representative samples for AF analysis for bulk lots of commodities. This is in part due to the fact that the aflatoxigenic molds do not grow uniformly in the matrices, giving a skewed distribution [94]. 
TABLE 6: Aflatoxin content of some staple foods in Uganda.

\begin{tabular}{|c|c|c|c|c|c|c|}
\hline \multirow{2}{*}{ Sample/matrix } & \multicolumn{3}{|c|}{ Number of samples } & \multicolumn{3}{|c|}{ Total aflatoxin $(\mu \mathrm{g} / \mathrm{kg})$} \\
\hline & Analyzed & AF positive & $\%$ AF positive & $1-100$ & $100-1000$ & $>1000$ \\
\hline Beans & 64 & 46 & 71.9 & 30 & 11 & 5 \\
\hline Maize & 49 & 22 & 44.9 & 13 & 9 & 0 \\
\hline Sorghum & 69 & 26 & 37.7 & 19 & 5 & 5 \\
\hline Peanuts & 152 & 27 & 17.8 & 11 & 8 & 8 \\
\hline Millet & 55 & 9 & 16.4 & 9 & 0 & 0 \\
\hline Peas & 19 & 3 & 15.8 & 3 & 0 & 0 \\
\hline Cassava & 34 & 4 & 11.8 & 0 & 2 & 2 \\
\hline Rice & 11 & 0 & $\mathrm{~N} / \mathrm{A}$ & 0 & 0 & 0 \\
\hline Other grains & 11 & 2 & 18.2 & 0 & 1 & 1 \\
\hline Grain mixtures & 16 & 3 & 18.7 & 2 & 0 & 0 \\
\hline Total & 480 & 142 & & 87 & 37 & 18 \\
\hline
\end{tabular}

Adapted from [93]. N/A: not applicable.

TABLE 7: Hepatoma incidence and frequency of aflatoxin contamination of some staple foods in Uganda.

\begin{tabular}{|c|c|c|c|c|c|c|}
\hline \multirow{3}{*}{ Region $^{\mathrm{a}}$} & \multirow{3}{*}{$\begin{array}{l}\text { Hepatoma cases/ } \\
100,000 \text { people per annum }\end{array}$} & \multicolumn{5}{|c|}{ Aflatoxigenic contamination } \\
\hline & & \multirow{2}{*}{$\begin{array}{l}\text { Analyzed } \\
\text { samples }\end{array}$} & \multirow{2}{*}{$\begin{array}{c}\% \text { of AF-positive } \\
\text { samples }\end{array}$} & \multicolumn{3}{|c|}{ Total aflatoxin $(\mu \mathrm{g} / \mathrm{kg})$} \\
\hline & & & & $1-100$ & $100-1000$ & $>1000$ \\
\hline Toro & No data collected & 29 & 79.3 & 10 & 31 & 38 \\
\hline Karamoja & 15.0 & 105 & 43.8 & 24 & 15 & 5 \\
\hline Buganda & $2.0-3.0$ & 149 & 28.9 & 23 & 4 & 1 \\
\hline West Nile & 2.7 & 26 & 23.1 & 19 & 4 & 0 \\
\hline Busoga & 2.4 & 39 & 10.3 & 05 & 5 & 0 \\
\hline Acholi & 2.7 & 26 & 15.4 & 15 & 0 & 0 \\
\hline Ankole & 1.4 & 37 & 10.8 & 11 & 0 & 0 \\
\hline Rwanda immigrants & 3.0 & $\begin{array}{c}\text { None } \\
\text { collected }\end{array}$ & $\begin{array}{c}\text { Not } \\
\text { applicable }\end{array}$ & $\begin{array}{c}\text { Not } \\
\text { applicable }\end{array}$ & $\begin{array}{c}\text { Not } \\
\text { applicable }\end{array}$ & $\begin{array}{c}\text { Not } \\
\text { applicable }\end{array}$ \\
\hline
\end{tabular}

Modified from [93]. Regions have different tribes with different traditional practices and ways of handling foods. ${ }^{\text {a}}$ Uganda is no longer divided into these regions, which have instead been made districts.

\subsection{Methods of Detection and Quantification Employed by AF} Investigations in Uganda. The methods for the detection of AFs in agricultural foods have been reviewed in sufficient details by some Ugandan authors [15]. This also explains, in part, the fact that most AF investigations in Uganda following this review such as that of Muzoora et al. [65], Echodu et al. [63], Wacoo et al. [67], and Byakika et al. [58] employed selective and highly sensitive methods. Table 8 summarizes some of the methods employed by aflatoxigenic investigations in Uganda.

Generally, aflatoxigenic analysis of samples employed laboratory-based high-performance liquid chromatography (HPLC), thin-layer chromatography (TLC), enzymelinked immunosorbent assays (ELISA), fluorescence spectrophotometry (FS), and liquid chromatography-tandem mass spectrometry (LC-MS/MS) which are expensive, labour-intensive, and time-consuming [15]. Unlike reported before [48], Uganda has developed some appreciable capacity to detect and quantify specific AFs with laboratories at Makerere University, Chemiphar Uganda Limited, Uganda National Bureau of Standards, Uganda Industrial Research Institute, and Directorate of Government Analytical laboratory. Unfortunately, all these laboratories are in the country's capital (Kampala) making them inaccessible to other regions. At industrial level, agroprocessing companies are monitoring total AFs in maize using single-step lateral flow immunoassays utilizing Reveal Q+ test strips that are developed and read on AccuSan Gold readers [46, 62].

Due to limited access to the aforelisted laboratory-based analytical methods, a rapid on-site AF portable immunosensor based on a glass-electroless-plated silver/cysteine platform for detection of total AF was constructed at Uganda Industrial Research Institute, plot 42A, Mukabya Road, Nakawa, Kampala, Uganda, by Wacoo and his teammates [97]. This electrochemical immunosensor device was subsequently validated in a penultimate study [64] which assessed the AF content of 60 maize flour samples in six principal markets and 72 samples from selected households in Metropolitan Kampala. The immunosensor was validated with a linear range of $0.7 \pm 0.1$ to $11.0 \pm 0.3 \mu \mathrm{g} / \mathrm{kg}$ and limit of detection of $0.7 \pm 0.0 \mu \mathrm{g} / \mathrm{kg}$. Maize flours from the scrutinized markets of Usafi, Nakawa, St. Balikuddembe (also called Owino), Nakasero, Kireka, and Kalerwe had a mean total AF of $7.6 \pm 2.3 \mu \mathrm{g} / \mathrm{kg}$ with approximately $20 \%$ of the samples having higher than $10 \mu \mathrm{g} / \mathrm{kg}$ statutory AF limit while $45 \%$ of household samples had total AF above compliance limit. The AF results from the immunosensor reportedly correlated with HPLC and ELISA results with correlation coefficients of 0.94 and 0.98 , respectively [64]. 
TABLE 8: Some of the analytical methods employed by aflatoxigenic investigations in Uganda.

\begin{tabular}{|c|c|c|c|}
\hline Method & Sample (s) & Year $^{\mathrm{a}}$ & References \\
\hline Lateral flow immunochromatography & Maize grain & 2019 & [62] \\
\hline HPLC & Maize-based product (Kwete) & 2019 & {$[67]$} \\
\hline ELISA & Sorghum, millet, obushera & 2019 & {$[58]$} \\
\hline ELISA, HPLC & Maize flour & 2018 & {$[64]$} \\
\hline ELISA & Maize, sorghum, millet, sesame, peanuts & 2018 & {$[63]$} \\
\hline HPLC & Human sera & 2018 & {$[92]$} \\
\hline TLC, ELISA & Peanuts (seeds and paste) & 2017 & {$[65]$} \\
\hline $\mathrm{LC} / \mathrm{MS} / \mathrm{MS}$ & Peanuts (seeds and paste) & 2017 & {$[66]$} \\
\hline FS & Peanuts (seeds and paste), cassava flour, maize grains & 2016 & {$[78]$} \\
\hline ELISA & Human sera & 2015 & {$[61]$} \\
\hline ELISA & Human sera & 2014 & [60] \\
\hline ELISA & Cereal-based baby foods & 2011 & [95] \\
\hline FS & Cassava & 2010 & {$[71]$} \\
\hline FS & $\begin{array}{l}\text { Sorghum, millet, Eshabwe, peanut (seeds and paste), } \\
\text { cassava chips }\end{array}$ & 2010 & {$[57]$} \\
\hline ELISA & Maize & 2006 & {$[96]$} \\
\hline FS & Peanuts & 2006 & [79] \\
\hline
\end{tabular}

${ }^{a}$ Years cited represent the years the data were published with most data collected in over 2 months to 1 year.

Bright greenish-yellow fluorescence (BGYF) or the black light test, which can locate lots presumed to be contaminated with AF, has not been reported in Uganda. This is a simple test for AF in maize where kernels are viewed under an ultraviolet lamp at $365 \mathrm{~nm}$ for characteristic bright greenishyellow fluorescence. This indicates a possible presence of aflatoxigenic fungi or the mycotoxin itself [98]. Regulatory bodies in Uganda should develop the capacity to perform this simple detection test for surveillance surveys.

3.2. Exposure Assessment. Humans are exposed to AFs through oral ingestion of contaminated plant products (such as peanuts) primarily as $\mathrm{AFB}_{1}$ or animal products such as meat and milk from animals previously fed on AF-contaminated feed (in the form of $\mathrm{AFM}_{1}$ ) [16]. Farmers and other agricultural workers may also get exposed by inhaling dust generated during the handling and processing of contaminated crops and feeds.

Analytical detection and quantification of AFs in foods do not give the exact exposure levels as the quantities detected in raw foods are not necessarily equivalent to that ingested. Losses are possible, and therefore, epidemiological biomarkers on dietary exposure have been employed to assess the level of exposure. Biomarkers are more precise for assessing the degree of exposure to AFs, as they are nonsubjective and can determine the internal and biologically effective doses. Aflatoxin biomarkers in use currently include the AF-N7-guanine adducts excreted in urine (reflect the previous day's exposure), $\mathrm{AFM}_{1}$ (primarily in breast milk, and reflects exposure over the previous 24 hours), and the aflatoxin-albumin adduct (AF-alb) in plasma or serum with half-life of about 2 months which allows assessment of chronic and routine exposure to AFs [99]. Albumin, the only serum protein that binds $A F B_{1}$, forms a high level of adducts [100], while haemoglobin binds $\mathrm{AFB}_{1}$ in a very low yield [101]. Albumin extracted from human blood and urine avails a measure of the biologically effective dose of ingested $\mathrm{AFB}_{1}$.
$\mathrm{AFB}_{1}$ and $\mathrm{AFG}_{1}$ can be bound by albumin and are metabolized to 8, 9-epoxide [102]. The AF-alb adduct levels are considered as $\mathrm{AFB}_{1}$ amount ingested as $\mathrm{AFG}_{1}$ is less prevalent in foods [38]. Thus, the AF-alb biomarker is the more commonly employed as it can be easily detected by ELISA (with results in pg AF-alb/mg albumin or in pg AFLys equivalent/mg alb) [103]. Quantification of $\mathrm{AFB}_{1}$-Lys in proteolytic digests of serum with HPLC-FS or LC-MS/MS has also been alternatively employed $[104,105]$.

In Uganda, Asiki et al. [60] reported human sera samples positive for AF-alb adducts in Southwestern Uganda. The AF-alb adduct ranged from 0 to $237.7 \mathrm{pg} / \mathrm{mg}$ alb among 100 adults (18-89 years) and 96 children ( $0-3$ years) with $75 \%$ of the participants having AF-alb adduct levels above $7.1 \mathrm{pg} / \mathrm{mg}$ alb and $50 \%$ having levels above $10.3 \mathrm{pg} / \mathrm{mg}$ alb while $25 \%$ had levels above $15.1 \mathrm{pg} / \mathrm{mg}$ alb. Overall, all the adults and four children had detectable AF-alb adducts in the study. Respondents living close to trading centers had significantly $(p=0.003)$ higher levels of detectable AF-alb adducts compared to their counterparts living in villages. Respondents consuming matooke (banana) had half detectable AFalbumin adduct compared to those who did not consume it. This is because these respondents are more likely to consume other foods which are prone to AF contamination; hence, people consuming matooke are less likely to have detectable AF-albumin adduct.

A longitudinal exposure study by Kang et al. [61] assessed AF exposure in Southwestern Uganda, reporting that $90 \%$ (642/713 of the sera) of samples drawn from the General Population Cohort were positive for AFB-Lys with a median level of $1.58 \mathrm{pg} / \mathrm{mg}$ and albumin range of $0.40-$ 168 pg/mg. AFB-Lys adducts from 1999 to 2003 in the Rakai Community Cohort Study showed a detection rate of $92.5 \%$ (346/374) with a median of $1.18 \mathrm{pg} / \mathrm{mg}$ and a range of $0.40-122.5 \mathrm{pg} / \mathrm{mg}$. Thus, it was deduced that AF exposure is high in the studied area and a similar finding is expected in other parts of Uganda. Further, a study done around the same time in the Northern part of Uganda [44] reported that 
there is a causal effect relationship between AF exposure and impaired growth in infants.

A cohort study by Lauer et al. [74] evaluated the association between maternal AF exposure during pregnancy and adverse birth outcomes, lower birth weight, in a sample of 220 mother-infant pairs in Mukono district, Uganda. Maternal AF exposure was assessed at $17.8 \pm 3.5 \mathrm{pg} / \mathrm{mg}$ week gestation. Anthropometry and birth outcome characteristics were obtained within 48 hours of delivery. Median maternal AFB-Lys level was $5.83 \mathrm{pg} / \mathrm{mg}$ alb (range: $0.71-95.60 \mathrm{pg} / \mathrm{mg}$ alb; interquartile range: $3.53-9.62 \mathrm{pg} / \mathrm{mg}$ alb). Increase in maternal AFB-Lys levels was significantly associated with lower weight $(p=0.040)$, lower weight-for-age $z$-score $(p=0.037)$, smaller head circumference $(p=0.035)$, and lower head circumference-for-age $z$-score $(p=0.023)$ in infants at birth. The team concluded that there is a correlation between maternal AF exposure during pregnancy and adverse birth outcomes, particularly lower birth weight and smaller head circumference, though these warrant further studies.

3.3. Coexposure Assessment with Other Mycotoxins. The likelihood that mycotoxins may interact synergistically to induce amplified toxicity in animals is high because toxigenic fungi often occur simultaneously in the same batch of food/matrix and some fungi are capable of simultaneously producing several mycotoxins in a single given substrate. Unfortunately, there are no data in the open literature in Uganda reporting on the assessment of coexposure of AFs with other important mycotoxins such as fumonisins, ochratoxins, trichothecenes, and zearalenone. The paucity of this data is partially due to the underdevelopment of valid biomarkers [106]. Mycotoxin-specific biomarkers for common mycotoxins such as fumonisins and deoxynivalenol have been developed only very recently $[107,108]$, and their utilization in epidemiological studies can be termed as nascent. Therefore, there is a need for assessment of coexposure to aflatoxins in Uganda with other mycotoxins.

\section{Prevention and Control}

4.1. International, Regional, and Statutory Efforts. Efforts have been put on AF control in Uganda through countrywide awareness creation [109-111]. This is being done by the Eastern Africa Grain Council (EAGC) in collaboration with Uganda National Bureau of Standards (UNBS) through the Eastern Africa Grain Institute with its headquarters at Muyenga, Kampala. Between 2015 and 2018, maize exporters, traders, farmer-based organizations, and warehouse handlers were trained on understanding the integrated East African maize standard (EAS 2:2013), food standardization, comparison of East African standards with international standards, standard maize sampling methods, maize grading, mycotoxins, and the available methods for mycotoxin analysis [112].

Since its launch in 2006, EAGC has been leading the fight against $\mathrm{AFs}$, working on a range of interventions to reduce the incidence, including assisting with the harmonization of $\mathrm{AF}$ control measures and improving the regulatory environment, running AF control training programs, providing moisture analyzers and tarpaulins to support farmers in drying and storing grains safely, sourcing for cheaper fieldbased AF testing kits and methods for measuring aflatoxins, conducting field surveys, regular analysis, and random sampling during harvesting at farm level to assess the prevalence and extent of contamination, working with East African Community to increase AF testing and surveillance in maize, participating in the development of the Partnership for Aflatoxin Control in Africa (PACA) strategy 2013-2022 as well as advising on the East African Community AF communication strategy [113].

National Agricultural Research Organization (NARO) in connection with Makerere University in 2010 developed a manual for the management of AF in peanuts [75]. The manual gives a general overview of AFs (structures, health, and economic effects), how to control AFs, and some of the farming practices in Uganda that favor AF growth. It was particularly drafted to provide ample guidance on the best practices in limiting AF contamination in peanuts and to raise the value of groundnuts and its products.

4.2. Scholarly Efforts. Probing investigations of Wacoo and his team [67] revealed that probiotic enrichment of a local maize-based traditional beverage (kwete) using starter culture with the probiotic Lactobacillus rhamnosus yoba 2012 and Streptococcus thermophilus $\mathrm{C} 106$ produced the beverage acceptable with consumers' acceptability score of greater/ equal to 6 on a 9-point hedonic scale. The beverage remained stable for a month with reported L. rhamnosus counts of $>10^{8} \mathrm{cfu} / \mathrm{g}, \mathrm{pH} 3.9$, and $0.6 \% \mathrm{w} / \mathrm{v}$ titratable acidity. AF analysis indicated that the water-soluble fraction of the beverage following fermentation had more than 1000-fold reduction in $\mathrm{AFB}_{1}, \mathrm{AFB}_{2}, \mathrm{AFG}_{1}$, and $\mathrm{AFG}_{2}$ initially spiked in the ingredients. The efficiency of L. rhamnosus to bind $\mathrm{AFB}_{1}$ was reported at $83.5 \%$ as determined by in vitro fluorescence spectroscopy.

Mold and total AF content of cereal flours and obushera (a local cereal-based beverage) from markets in metropolitan Kampala were evaluated by Byakika et al. [58]. The capacity of lactic acid bacteria (LAB) starters from obushera, L. plantarum MNC 21, Weissella confusa MNC 20, and L. lactis MNC 24 to bind $\mathrm{AFB}_{1}$ was evaluated against L. rhamnosus yoba 2012 (as a reference starter strain). The authors reported that mold counts in sorghum, millet, and obushera were between 0.0-2.4 log cfu/g, 2.0$6.5 \log \mathrm{cfu} / \mathrm{g}$, and 2.0-5.5 $\log \mathrm{cfu} / \mathrm{g}$, respectively. The mold counts in all the flours as reported exceeded the maximum food safety compliance limit of $4.0 \mathrm{log} \mathrm{cfu} / \mathrm{g}$ of molds; $88.0 \%$ of obushera had counts within the maximum compliance limit of $1.3 \log \mathrm{cfu} / \mathrm{g}$. Aflatoxigenic results revealed that total AF content of investigated matrices (sorghum, millet, and obushera), respectively, in $\mu \mathrm{g} / \mathrm{kg}$ were $22.3 \pm 21.2,9.9 \pm 10.0$, and $10.4 \pm 6.1$. The LAB bound $19.3-69.4 \%$ of $\mathrm{AFB}_{1}$ in a $1000 \mu \mathrm{g} / \mathrm{kg}$ matrix, with binding 
efficiency in the order of $L$. rhamnosus yoba $2012=L$. plantarum MNC $21>W$. confusa MNC $20=$ L. lactis $\mathrm{MNC}$ 24. The $\mathrm{LAB}_{-} \mathrm{AFB}_{1}$ complex was reportedly stable to physiological saline washes, indicating that the LAB with AF-binding properties can be harnessed for controlled fermentation to reduce AF content of obushera [58].

4.3. Suggested Management Strategies. The following control measures are suggested by this review for the control of AFs.

4.3.1. Preharvest Management. Crop varieties that are less susceptible to fungal growth should be bred and planted. This has been reported to be one of the best approaches for reducing the effects of mycotoxin-producing fungal species [114]. Thus, local varieties of crops resistant to AF-producing fungi warrant investigation as some studies have unveiled that some local maize cultivars had lower AF levels than imported varieties [115]. In Uganda, Serenut 2 (a peanut variety) has been cited as a genetically more resistant variety to fungal growth and the production of AFs [76]. Drought, disease, and pest-tolerant/resistant crop varieties have been found to greatly reduce AF contamination. More so, host and parasite macro- and micromolecular trafficking that suggests the possibility to circumvent the AF problem by use of cross-species RNA interference has been suggested. This equips particularly maize with molecules that shuts down AF biosynthesis upon infection with aflatoxigenic fungi, thwarting AF accumulation.

Timely harvesting of grains with the husks upon maturity in dry conditions and early removal of any damaged maize kernels or cobs is a feasible AF reduction strategy [115].

Visual sorting, winnowing, washing, crushing, and dehulling have been found to contribute up to a $40-80 \%$ reduction in AF levels in grains $[116,117]$. Sorting is highly recommended for reducing AF content in foods, peculiarly in peanuts $[115,118-120]$ and cassava. However, sorting and giving children the molded peanuts (called "lake" in Northern Uganda) or using them for making peanut paste should be discouraged. Sorting can be done using clean water; the damaged seeds or grains are buoyant while good ones sink and can be cooked directly. This is traditionally practiced in Northern Uganda with beans, peas, and cowpeas. Soaking and cooking in magadi soda, malting, and roasting are other methods that have been used to reduce the levels of AFs in maize [117, 121-123]. Magadi soda is unknowingly used by the rural community of Lango subregion as a catalyst for fastening the cooking of beans, peas, white ants, and sesame-based dishes (alakena and agwaca), vegetables, and sometimes cassava.

Protection of crops from pest attack is key in aflatoxin management. This can be done using ash while in storage as is done in maize $[124,125]$ and plant essential oils such as Eucalyptus saligna that have reported bioinsecticidal activity [126].

Biocontrol strategies employing concoctions from plants have been investigated and reported to inhibit $A$. flavus mycelial growth and proliferation. Essential oils of $A z a-$ dirachta indica (neem) and Morinda lucida have been reported to retard aflatoxigenic A. flavus growth and its AF biosynthesis potential in inoculated maize grains [127]. Powder of Aframomum danielli (Zingiberaceae) can regulate molds and insect infestation in maize and soybeans in storage for over a year under ambient conditions [128].

Competitive exclusion has been reported as a feasible AF control strategy. A. flavus strains differ in AF production and this influences their crop contamination potential. The toxigenic strains (" $\mathrm{S}$ " strains) produce a lot of AFs with numerous small sclerotia $(<400 \mu \mathrm{m})$ whereas the " $\mathrm{L}$ " strains are atoxigenic and comparatively produce lower AF levels and a few large sclerotia that are $>400 \mu \mathrm{m}$ [129]. There is always competitive exclusion when one strain competes to exclude another in the environment. Thus, a shift of strain profile from toxigenic to atoxigenic is a viable biological control strategy. This competitive exclusion strategy has yielded good results in some investigations with up to $96 \%$ reduction in AF levels [129].

A biopesticide, consisting of a rhizosphere-competent nonaflatoxigenic strain of Aspergillus with competitive saprophytic ability, may competitively exclude toxigenic strains from infecting the crop. Fluorescent pseudomonads and several strains of Trichoderma species inhabit the rhizosphere of many crop plants and have been identified as potentially promising biocontrol agents against $A$. flavus. Since the beginning of the $21^{\text {st }}$ century, many Trichoderma (>250) and Pseudomonas (>100) species have been isolated from peanut rhizosphere and evaluated for their antagonism towards $A$. flavus and their ability to reduce preharvest kernel infection of peanuts. Significant reduction of A. flavus populations and kernel infection occurred in both greenhouse and field experiments. Two Trichoderma isolates, Tv 47 and Tv 23, and two bacterial isolates, $P$. cepacia (B 33) and P. fluorescens (Pf 2), were effective in reducing aflatoxin content in the kernels. Control of AF contamination has also been reported to be effective using nonaflatoxigenic biocontrol $A$. flavus strains that outcompete the wild strain, reducing their concentration at the contaminated site [130]. However, the efficacy of these agents warrants establishment under Ugandan conditions so that affordable, readily available, and effective formulations can be developed for use.

4.3.2. Postharvest Management. The cost of prevention versus the cost of cure is not a new debate, and thus, some cure technologies for AFs are in place. One of the credited strategies is to reduce the moisture content of harvested food crops to safe storage levels (12-14\%). Harvested crops should be shelled and cleaned prior to storage to reduce incidences of pest infestation which may promote aflatoxigenic contamination [59]. Further, storage facilities should be well ventilated to ensure temperatures between $25^{\circ} \mathrm{C}$ and $32^{\circ} \mathrm{C}$ and sustained relative humidity above $65 \%$ suitable for aflatoxin growth are not attained [131]. According to Sumner and Lee [132], temperatures below $18^{\circ} \mathrm{C}$ and moisture of $12-13 \%$ usually stop the development of Aspergillus fungi.

Clays such as Novasil Plus (NSP; BASF Corp., Ludwigshafen, Germany) have been demonstrated to bind AF in 
animal feeds [133] and reduce its content. An innovation for postharvest AF elimination called the "Toxin Scrub" has been demonstrated by Grain and Toxins Ltd in Uganda, but its usage has been delimited by its prohibitive cost [47]. The technology utilizes ozone, a strong oxidizer to eliminate nearly all the mycotoxins in the grain. This is supported by the fact that AFs are unstable to UV light in the presence of oxygen, to extremes of $\mathrm{pH}(<3,>10)$ and to oxidizing agents such as sodium hypochlorite, potassium permanganate, chlorine, hydrogen peroxide, ozone, and sodium perborate [20]. AFs are also degraded by reaction with ammonia, various amines, and sodium hypochlorite. Some compounds such as curcumin can alter the microsomal activation of $\mathrm{AFB}_{1}$ and reduce the $\mathrm{AFB}_{1}$ toxicity by increasing its detoxification.

Chemoprotection against AFs consumed by animals has also been reported. It utilizes compounds such as esterified glucomanoses and other yeast extracts that increase the animal's detoxification process or otherwise prevent the production of AF-epoxide, thereby reducing or blocking $\mathrm{AFB}_{1}$-induced hepatocarcinogenesis. Oltipraz and chlorophyll are used to reduce the biologically effective dose and act by binding AFs, thereby rendering them biologically unavailable to humans and animals.

4.4. Treatment of Aflatoxicosis. No scientifically proven specific antidote for ingested AFs has been reported. However, the timely use of 1 -methionine $(200 \mathrm{mg} / \mathrm{kg})$ and sodium thiosulfate $(50 \mathrm{mg} / \mathrm{kg})$ after every 8 hours has reported therapeutic significance. Dietary intake of protein, vitamins, and antioxidants can be encouraged in case of aflatoxicosis [134].

\section{Conclusion}

Aflatoxin surveillance in Uganda is done through a reactive approach. Ugandan foods are mycotoxicologically contaminated with aflatoxins, and this has serious health implications. No study in Uganda has assessed AFs in beers, imported rice such as basmati, and sugarcane despite them being daily consumables. The Ugandan government through its ministries should develop the capacity to detect, quantify, monitor, and regulate AFs in foods produced and sold within the country and those exported/imported. There is a need for more aflatoxin exposure assessments as well as coexposure to aflatoxins with other mycotoxins.

\section{Conflicts of Interest}

The authors declare that there are no conflicts of interest regarding the publication of this paper.

\section{Acknowledgments}

The authors are grateful to the World Bank and the InterUniversity Council of East Africa for the scholarship awarded to Timothy Omara and Winfred Nassazi through the Africa Center of Excellence II in Phytochemicals, Textiles and Renewable Energy (ACE II-PTRE) at Moi University that made them realize this communication.

\section{References}

[1] R. Bhat, R. V. Rai, and A. A. Karim, "Mycotoxins in food and feed: present status and future concerns," Comprehensive Reviews in Food Science and Food Safety, vol. 9, no. 1, pp. 57-81, 2010.

[2] M. Reverberi, A. Ricelli, S. Zjalic, A. A. Fabbri, and C. Fanelli, "Natural functions of mycotoxins and control of their biosynthesis in fungi," Applied Microbiology and Biotechnology, vol. 87, no. 3, pp. 899-911, 2010.

[3] J. I. Pitt, C. Wild, R. A. Baan et al., Improving Public Health through Mycotoxin Control, IARC Scientific Publication No. 158, IARC, Lyons, France, 2012.

[4] W. P. Blount, "Turkey X disease," Journal of British Turkey Federation, vol. 9, no. 52, pp. 52-61, 1961.

[5] J. L. Richard, "Discovery of aflatoxins and significant historical features," Toxin Reviews, vol. 27, no. 3-4, pp. 171-210, 2008.

[6] K. Sargeant, A. Sheridan, J. O'Kelly, and R. B. A. Carnaghan, "Toxicity associated with certain samples of groundnuts," Nature, vol. 192, no. 4807, pp. 1096-1097, 1961.

[7] W. P. Blount, "A new Turkey disease problem in England," British Oil and Cake Mills Limited, Quarterly Poultry Bulletin, vol. 27, pp. 1-3, 1960.

[8] R. Allcroft, "Aspects of aflatoxicosis in farm animals," in Mycotoxins in Foodstuffs: Proceedings of MIT Symposium, March 18-19, 1964, G. N. Wogan, Ed., pp. 153-162, Cambridge University Press, Cambridge, MA, USA, 1965.

[9] J. D. Thrasher, Aflatoxicosis in Animals. Aflatoxins and Health, 2012, http://www.alphaboostjuice.com/AFLATOXICOSIS_ IN_ANIMALS.pdf.

[10] A. Ciegler, "Mycotoxins: occurrence. chemistry, biological activity," Lloydia, vol. 38, no. 1, pp. 21-35, 1975.

[11] Q. Wu, A. Jezkova, Z. Yuan, L. Pavlikova, V. Dohnal, and K. Kuca, "Biological degradation of aflatoxins," Drug Metabolism Reviews, vol. 41, no. 1, pp. 1-7, 2009.

[12] J. W. Bennett and M. Klich, "Mycotoxins," Clinical Microbiology Reviews, vol. 16, no. 3, pp. 497-516, 2003.

[13] INCHEM, Principles of Evaluating Chemical Effects on the Aged Population: International Programme on Chemical Safety-Environmental Health Criteria 144, World Health Organization, Geneva, Switzerland, 1993.

[14] H. S. Chun, H. J. Kim, H. E. Ok, J.-B. Hwang, and D.-H. Chung, "Determination of aflatoxin levels in nuts and their products consumed in South Korea," Food Chemistry, vol. 102, no. 1, pp. 385-391, 2007.

[15] A. P. Wacoo, D. Wendiro, P. C. Vuzi, and J. F. Hawumba, "Methods for detection of aflatoxins in agricultural food crops," Journal of Applied Chemistry, vol. 2014, Article ID 706291, 15 pages, 2014.

[16] World Health Organization, Environmental Health Criteria, Safety Evaluation of Certain Food Additives, IP: VI: 1 Resources, World Health Organization, Geneva, Switzerland, 1979.

[17] World Health Organization, Hazardous Chemicals in Humans and Environmental Health: International Programme on Chemical Safety, World Health Organization, Geneva, Switzerland, 2000.

[18] T. Otsuki, J. S. Wilson, and M. Sewadeh, A Race to the Top? A Case Study of Food Safety Standards and African Exports, 
Development Research Group (DECRG), World Bank, Washington, DC, USA, 2002.

[19] D. L. Sudakin, "Dietary aflatoxin exposure and chemoprevention of cancer: a clinical review," Journal of Toxicology: Clinical Toxicology, vol. 41, no. 2, pp. 195-204, 2003.

[20] S. Okoth, Improving the Evidence Base on Aflatoxin Contamination and Exposure. Series: Agriculture and Nutrition, The Technical Centre for Agricultural and Rural Cooperation, Wageningen, The Netherlands, CTA Working Paper 16/13, 2016.

[21] R. E. Black, C. G. Victora, S. P. Walker et al., "Maternal and child undernutrition and overweight in low-income and middle-income countries," The Lancet, vol. 382, no. 9890, pp. 427-451, 2013.

[22] A. Iyanda, J. Anetor, D. Oparinde, and F. Adeniyi, "Aflatoxin contamination of foodstuffs: its health implications in subSaharan Africa," Annals of Experimental Biology, vol. 2, no. 3, pp. 63-73, 2014.

[23] B. Udovicki, K. Audenaert, S. De Saeger, and A. Rajkovic, "Overview on the mycotoxins incidence in Serbia in the period 2004-2016," Toxins, vol. 10, no. 7, p. 279, 2018.

[24] G. Perrone, A. Gallo, and A. F. Logrieco, "Biodiversity of Aspergillus section Flavi in Europe in relation to the management of aflatoxin risk," Frontiers in Microbiology, vol. 5, p. 377, 2014.

[25] N. Baranyi, S. Kocsube, C. Vagvolgyi, and J. Varga, "Current trends in aflatoxin research," Acta Biologica Szegediensis, vol. 57, pp. 95-107, 2013.

[26] B. W. Horn, "Aspergillus caelatus, a new species in section Flavi,” Mycotaxon, vol. 61, pp. 185-192, 1997.

[27] Y. Ito, S. W. Peterson, D. T. Wicklow, and T. Goto, “Aspergillus pseudotamarii, a new aflatoxin producing species in Aspergillus section Flavi," Mycological Research, vol. 105, no. 2, pp. 233-239, 2001.

[28] S. W. Peterson, Y. Ito, B. W. Horn, and T. Goto, “Aspergillus bombycis, a new aflatoxigenic species and genetic variation in its sibling species, A. nomius," Mycologia, vol. 93, no. 4, pp. 689-703, 2001.

[29] M. B. Pildain, J. C. Frisvad, G. Vaamonde, D. Cabral, J. Varga, and R. A. Samson, "Two novel aflatoxin-producing Aspergillus species from Argentinean peanuts," International Journal of Systematic and Evolutionary Microbiology, vol. 58, no. 3, pp. 725-735, 2008.

[30] J. Varga, J. C. Frisvad, and R. A. Samson, "Two new aflatoxin producing species, and an overview of Aspergillus section Flavi," Studies in Mycology, vol. 69, no. 1, pp. 57-80, 2012.

[31] J. Varga, N. Baranyi, M. Chandrasekaran, C. Vágvölgyi, and S. Kocsubé, "Mycotoxin producers in the Aspergillus genus: an update," Acta Biologica Szegediensis, vol. 59, no. 2, pp. 151-167, 2015.

[32] J. Varga, J. Frisvad, and R. Samson, "A reappraisal of fungi producing Aflatoxins," World Mycotoxin Journal, vol. 2, no. 3, pp. 263-277, 2009.

[33] J. D. Groopman and T. W. Kensler, "Role of metabolism and viruses in aflatoxin-induced liver cancer," Toxicology and Applied Pharmacology, vol. 206, no. 2, pp. 131-137, 2005.

[34] T. W. Kensler, B. D. Roebuck, G. N. Wogan, and J. D. Groopman, "Aflatoxin: a 50-year odyssey of mechanistic and translational toxicology," Toxicological Sciences, vol. 120, no. Supplement 1, pp. S28-S48, 2011.

[35] K. D. Raney, D. J. Meyer, B. Ketterer, T. M. Harris, and F. P. Guengerich, "Glutathione conjugation of aflatoxin B1 exo- and endo-epoxides by rat and human glutathione
S-transferases," Chemical Research in Toxicology, vol. 5, no. 4, pp. $470-478,1992$.

[36] J. K. Jewers, Mycotoxins and their Effect on Poultry Production, Tropical Development and Research Institute (TDRI), London, UK, 2015.

[37] D. M. Dereszynski, S. A. Center, J. F. Randolph et al., "Clinical and clinicopathologic features of dogs that consumed foodborne hepatotoxic aflatoxins: 72 cases (20052006)," Journal of the American Veterinary Medical Association, vol. 232, no. 9, pp. 1329-1337, 2008.

[38] B. I. Agag, "Mycotoxins in foods and feeds: aflatoxins," Assiut University Bulletin for Environmental Researches, vol. 7, pp. 173-206, 2004.

[39] J. F. Robens and J. L. Richard, "Aflatoxins in animal and human health," Reviews of Environmental Contamination and Toxicology, vol. 27, pp. 69-94, 1992.

[40] F. Wu, C. Narrod, M. Tiongco, and Y. Liu, The Health Economics of Aflatoxin: Global Burden of Disease, International Food Policy Research Institute, Washington, DC, USA, 2011.

[41] PACA News, "Quarterly newsletter of the partnership for aflatoxin control in Africa-African Union," vol. 5, no. 2, 2018.

[42] W. J. William, T. D. Phillips, P. E. Jolly et al., "Human aflatoxicoses in developing countries: a review of toxicology exposure, potential health consequences and interventions," American Journal of Clinical Nutrition, vol. 80, no. 4, pp. 1106-1122, 2003.

[43] P. Khlangwiset, G. S. Shephard, and F. Wu, "Aflatoxins and growth impairment: a review," Critical Reviews in Toxicology, vol. 41, no. 9, pp. 740-755, 2011.

[44] B. Natamba, V. Okoth-Ogola, and N. Pen-Mogi, Update on Progress with Prenaps and Postnaps Studies in Gulu Northern Uganda, Feed the Future Nutrition Innovation Lab-Africa Annual Report Year 4 (2013-2014), Gulu University, Gulu, Uganda, 2015

[45] Y. Jiang, P. E. Jolly, W. O. Ellis, J.-S. Wang, T. D. Phillips, and J. H. Williams, "Aflatoxin B1 albumin adduct levels and cellular immune status in Ghanaians," International Immunology, vol. 17, no. 6, pp. 807-814, 2005.

[46] New Vision, EAGC Gives Equipment to Detect Aflatoxins, 30th December 2016, http://googleweblight.com/i?u=https:// www.newvision.co.ug/new_vision/news/1443062/eagcequipment-detect-aflatoxins\&hl=en-UG.

[47] Daily Monitor, New Technology to Clean Aflatoxins from Grains, April 2019, http://mobile.monitor.co.ug/Business/ Business/New-technology-to-clean-aflatoxins-from-grains/ 2471012-5062312-format-xhtml-s6h8wgz/index.html.

[48] N. A. Kaaya and H. L. Warren, "A review of past and present research on aflatoxin in Uganda," African Journal of Food, Agriculture and Nutritional Development, vol. 5, no. 1, pp. 1-18, 2005.

[49] C. Soares, P. Rodrigues, S. W. Peterson, N. Lima, and A. Venâncio, "Three new species of Aspergillus section flavi isolated from almonds and maize in Portugal," Mycologia, vol. 104, no. 3, pp. 682-697, 2012.

[50] A. C. Baquião, M. M. M. de Oliveira, T. A. Reis, P. Zorzete, D. Diniz Atayde, and B. Correa, "Polyphasic approach to the identification of Aspergillus section Flavi isolated from Brazil nuts," Food Chemistry, vol. 139, no. 1-4, pp. 1127-1132, 2013.

[51] C. M. Jolly, B. Bayard, R. T. Awuah, S. C. Fialor, and J. T. Williams, "Examining the structure of awareness and perceptions of groundnut aflatoxin among Ghanaian health and agricultural professionals and its influence on their 
actions," The Journal of Socio-Economics, vol. 38, no. 2, pp. 280-287, 2009.

[52] R. M. Sabran, M. Redzwan, A. Jamaluddin et al., "Sociodemographic and socio-economic determinants of adults' knowledge on fungal and aflatoxin contamination in the diets," Asian Pacific Journal of Tropical Biomedicine, vol. 2, no. 3, pp. S1835-S1841, 2012.

[53] K. S. Kaushal and D. Bhatnagar, Mycotoxins in Agriculture and Food Safety, CRC Press, London, UK, 1998.

[54] G. R. O’Brian, D. R. Georgianna, J. R. Wilkinson et al., "The effect of elevated temperature on gene transcription and AF biosynthesis," Mycologia, vol. 99, no. 2, pp. 232-239, 2007.

[55] J. Yu, N. D. Fedorova, B. G. Montalbano et al., "Tight control of mycotoxin biosynthesis gene expression in Aspergillus flavus by temperature as revealed by RNA-Seq," FEMS Microbiology Letters, vol. 322, no. 2, pp. 145-149, 2011.

[56] F. B. Lukwago, I. M. Mukisa, A. Atukwase, A. N. Kaaya, and S. Tumwebaze, "Mycotoxins contamination in foods consumed in Uganda: a 12-year review (2006-2018)," Scientific African, vol. 3, Article ID e00054, 2019.

[57] D. Kitya, G. Bbosa, and E. Mulogo, "Aflatoxin levels in common foods of South Western Uganda: a risk factor to hepatocellular carcinoma," European Journal of Cancer Care, vol. 19, no. 4, pp. 516-521, 2019.

[58] S. Byakika, I. M. Mukisa, A. P. Wacoo, R. Kort, Y. B. Byaruhanga, and C. Muyanja, "Potential application of lactic acid starters in the reduction of aflatoxin contamination in fermented sorghum-millet beverages," International Journal of Food Contamination, vol. 6, no. 4, 2019.

[59] A. N. Kaaya and W. Kyamuhangire, "The effect of storage time and agroecological zone on mould incidence and aflatoxin contamination of maize from traders in Uganda," International Journal of Food Microbiology, vol. 110, no. 3, pp. 217-223, 2006.

[60] G. Asiki, J. Seeley, C. Srey et al., "A pilot study to evaluate aflatoxin exposure in a rural Ugandan population," Tropical Medicine \& International Health, vol. 19, no. 5, pp. 592-599, 2014.

[61] M.-S. Kang, P. Nkurunziza, R. Muwanika et al., "Longitudinal evaluation of aflatoxin exposure in two cohorts in South-Western Uganda," Food Additives \& Contaminants: Part A, vol. 32, no. 8, pp. 1322-1330, 2015.

[62] T. Omara, "Aflatoxigenic contamination of white maize (Zea mays L.) from some selected Ugandan districts," Peer J Preprints, vol. 7, Article ID e27888v1, 2019.

[63] R. Echodu, H. Edema, G. M. Malinga et al., "Is nodding syndrome in Northern Uganda linked to consumption of mycotoxin contaminated food grains?" BMC Research Notes, vol. 11, no. 1, p. 678, 2018.

[64] A. P. Wacoo, D. Wendiro, S. Nanyonga et al., "Feasibility of a novel on-site detection method for aflatoxin in maize flour from markets and selected households in Kampala, Uganda," Toxins, vol. 10, no. 8, p. 327, 2018.

[65] S. Muzoora, M. Khaitsa, H. Bailey, and P. Vuzi, "Status of aflatoxin levels in groundnuts in Uganda," The Pan African Medical Journal, vol. 27, no. 2 (Supp 4), p. 11, 2017.

[66] S. A. Baluka, D. Schrunk, P. M. Imerman et al., "Mycotoxin and metallic element concentrations in peanut products sold in Ugandan markets," Cogent Food and Agriculture, vol. 3, p. 1313925, 2017.

[67] A. Wacoo, I. Mukisa, R. Meeme et al., "Probiotic enrichment and reduction of aflatoxins in a traditional African maizebased fermented food," Nutrients, vol. 11, no. 2, p. 265, 2019.
[68] B. Warth, A. Parich, J. Atehnkeng et al., "Quantitation of mycotoxins in food and feed from Burkina Faso and Mozambique using a modern LC-MS/MS multitoxin method," Journal of Agricultural and Food Chemistry, vol. 60, no. 36, pp. 9352-9363, 2012.

[69] S. Lee, S. Lee, J. P. Sserumaga et al., "Survey for contamination of aflatoxin in Uganda maize," Journal of the Korean Society of International Agriculture, vol. 25, no. 4, pp. 335340, 2013.

[70] A. Lopez and M. A. Crawford, "Aflatoxin content of groundnuts sold for human consumption in Uganda," The Lancet, vol. 290, no. 7530, pp. 1351-1354, 1967.

[71] A. N. Kaaya and D. Eboku, "Mould and aflatoxin contamination of dried cassava chips in Eastern Uganda: association with traditional processing and storage practices," Journal of Biological Sciences, vol. 10, no. 8, pp. 718-729, 2010.

[72] H. K. Taligoola, M. A. Ismail, and S. K. Chebon, "Toxigenic fungi and aflatoxins associated with marketed rice grains in Uganda," Journal of Basic and Applied Mycology, vol. 1, pp. 45-52, 2010.

[73] T. K. Sebunya and D. M. Yourtee, "Aflatoxigenic Aspergilli in foods and feeds in Uganda," Journal of Food Quality, vol. 13, no. 2, pp. 97-107, 1990.

[74] J. M. Lauer, C. P. Duggan, L. M. Ausman et al., "Maternal aflatoxin exposure during pregnancy and adverse birth outcomes in Uganda," Maternal and Child Nutrition, vol. 15, no. 2, Article ID e12701, 2019.

[75] D. K. Okello, M. Biruma, and C. M. Deom, "Overview of groundnuts research in Uganda: past, present and future," African Journal of Biotechnology, vol. 9, pp. 6448-6459, 2010.

[76] D. K. Okello, A. N. Kaaya, J. Bisikwa, M. Were, and H. K. Oloka, Management of Aflatoxins in Groundnuts: A Manual for Farmers, Processors, Traders and Consumers in Uganda, National Agricultural Research Organisation, Entebbe, Uganda, 2010, ISBN: 978-9970-401-00-0.

[77] M. Korobkin and E. H. Williams, "Hepatoma and groundnuts in the West Nile districts of Uganda," Yale Journal of Biology and Medicine, vol. 41, pp. 69-78, 1968.

[78] J. Osuret, G. Musinguzi, T. Mukama et al., "Aflatoxin contamination of selected staple foods sold for human consumption in Kampala markets, Uganda," Journal of Biological Sciences, vol. 16, no. 1, pp. 1-5, 2016.

[79] A. N. Kaaya, C. Harris, and W. Eigel, "Peanut aflatoxin levels on farms and in markets of Uganda," Peanut Science, vol. 33, no. 1, pp. 68-75, 2006.

[80] Partnership for Aflatoxin Control in Africa (PACA), Country-Led Aflatoxin and Food Safety Situation Analysis and Action Planning for Uganda: Final Report, PACA, African Union Commission, Addis Ababa, Ethiopia, 2017, http:// www.aflatoxinpartnership.org/uploads/Uganda_Aflatoxin_ Control_M.

[81] A. Seetha, W. Munthali, H. W. Msere et al., "Occurrence of aflatoxins and its management in diverse cropping systems of central Tanzania," Mycotoxin Research, vol. 33, no. 4, pp. 323-331, 2017.

[82] Building an Aflatoxin Safe East African Community, Technical Policy Paper 8, Aflatoxin Standards for Food Knowledge Platform 2015, Situational Analysis East Africa Region, 30 pages, http://aflasafe.com/wp-content/uploads/ pdf/TPP-8-Aflatoxin-Standards-for-Food.pdf.

[83] A. J. A. Essers, C. Ebong, R. M. van der Grift, M. J. R. Nout, W. Otim-Nape, and H. Rosling, "Reducing cassava toxicity by heap-fermentation in Uganda," International Journal of Food Sciences and Nutrition, vol. 46, no. 2, pp. 125-136, 1995. 
[84] T. Omara, S. Ndyamuhaki, E. Kigenyi, S. Kagoya, and F. Biira, "Comparative evaluation of the microbial safety of boiled locally vended ready-to-drink, HTST pasteurized and UHT bovine milk sold in Nakawa division of Metropolitan Kampala," International Journal of Food Science and $\mathrm{Nu}$ trition, vol. 3, no. 6, pp. 185-189, 2018.

[85] Daily Monitor, Saturday 25th February 2017, Eshabwe, a Local Delicacy, http://www.monitor.co.ug/artsculture/DiningRecipes/Eshabwe-a-local-delicacy/691226-3826228-nacli9z/ index.html.

[86] A. W. Yunus, E. Razzazi-Fazeli, and J. Bohm, "Aflatoxin B1 in affecting broiler's performance, immunity, and gastrointestinal tract: a review of history and contemporary issues," Toxins, vol. 3, no. 6, pp. 566-590, 2011.

[87] G. J. A. Speijers and M. H. M. Speijers, "Combined toxic effects of mycotoxins," Toxicology Letters, vol. 153, no. 1, pp. 91-98, 2004.

[88] A. Stevens, C. Saunders, J. Spence et al., "Investigations into "diseases" of Turkey poults," Veterinary Record, vol. 72, pp. 627-628, 1960.

[89] M. Ozturk, "P53 mutation in hepatocellular carcinoma after aflatoxin exposure," Lancet, vol. 338, pp. 1356-1359, 1991.

[90] A. Serck-Hanssen, "Aflatoxin-induced fatal hepatitis?" Archives of Environmental Health: An International Journal, vol. 20, no. 6, pp. 729-731, 1970.

[91] E. Alpert, A. Serck-Hanssen, and B. Rajagopolan, "Aflatoxininduced hepatic injury in the African monkey," Archives of Environmental Health: An International Journal, vol. 20, no. 6, pp. 723-728, 1970.

[92] R. Kajobe, E. K. Kato, S. A. Otim, P. Kasangaki, and P. P. Abila, "The status of honeybee pests in Uganda," Bulletin of Animal Health and Production in Africa, pp. 105-117, 2016.

[93] M. E. Alpert, M. S. R. Hutt, G. N. Wogan, and C. S. Davidson, "Association between aflatoxin content of food and hepatoma frequency in Uganda," Cancer, vol. 28, no. 1, pp. 253-260, 1971.

[94] N. W. Turner, S. Subrahmanyam, and S. A. Piletsky, "Analytical methods for determination of mycotoxins: a review," Analytica Chimica Acta, vol. 632, no. 2, pp. 168-180, 2009.

[95] M. A. Ismail, H. Taaligoola, and R. Nakamya, "Toxigenic mycobiota associated with baby foods locally produced in Uganda with special reference to aflatoxins," Journal of Basic and Applied Mycology, vol. 2, pp. 55-67, 2011.

[96] G. Bigirwa, G. Sseruwu, A. N. Kaaya, E. Adipala, and S. Okanya, "Fungal microflora causing maize ear rots in Uganda and associated aflatoxins," Journal of Biological Sciences, vol. 6, no. 3, pp. 540-546, 2006.

[97] A. P. Wacoo, M. Ocheng, D. Wendiro, P. C. Vuzi, and F. J. Hawumba, "Development and characterization of an electroless plated silver/cysteine sensor platform for the electrochemical determination of aflatoxin B1," Journal of Sensors, vol. 2016, Article ID 3053019, 8 pages, 2016.

[98] H. Yao, Z. Hruska, R. Kincaid, R. Brown, T. Cleveland, and D. Bhatnagar, "Correlation and classification of single kernel fluorescence hyperspectral data with aflatoxin concentration in corn kernels inoculated withAspergillus flavusspores," Food Additives \& Contaminants: Part A, vol. 27, no. 5, pp. 701-709, 2010.

[99] M. N. Routledge and Y. Y. Gong, "Developing biomarkers of human exposure to mycotoxins," in Determining Mycotoxins and Mycotoxigenic Fungi in Food and Feed, S. De Saeger, Ed., pp. 225-244, Woodhead Publishing, Cambridge, UK, 2011.
[100] P. L. Skipper, D. H. Hutchins, R. J. Turesky et al., "Carcinogen binding to serum-albumin," in Proceedings of the American Association for Cancer Research, American Association for Cancer Research, Houston, TX, USA, February 1985.

[101] S. Tannenbaum and P. L. Skipper, "Biological aspects to the evaluation of risk: dosimetry of carcinogens in man," Fundamental and Applied Toxicology, vol. 4, no. 3, pp. S367S373, 1984.

[102] S. Egal, A. Hounsa, Y. Y. Gong et al., "Dietary exposure to aflatoxin from maize and groundnut in young children from Benin and Togo, West Africa," International Journal of Food Microbiology, vol. 104, no. 2, pp. 215-224, 2005.

[103] B. Chapot and C. P. Wild, "ELISA for quantification of AFalb adducts and their application to human exposure assessment," in Techniques in Diagnostic Pathology, M. Warhol, D. van Velzen, and G. R. Bullock, Eds., pp. 1-13, Academic Press, San Diego CA, USA, 1991.

[104] G. Sabbioni, S. Ambs, G. N. Wogan, and J. D. Groopman, "The aflatoxin-lysine adduct quantified by high-performance liquid chromatography from human serum albumin samples," Carcinogenesis, vol. 11, no. 11, pp. 2063-2066, 1990.

[105] P. F. Scholl, L. McCoy, T. W. Kensler, and J. D. Groopman, "Quantitative analysis and chronic dosimetry of the aflatoxin B1Plasma albumin adduct lys-AFB1in rats by isotope dilution mass spectrometry," Chemical Research in Toxicology, vol. 19, no. 1, pp. 44-49, 2006.

[106] Y. Y. Gong, S. Watson, and M. N. Routledge, "Aflatoxin exposure and associated human health effects, a review of epidemiological studies," Food Safety, vol. 4, no. 1, pp. 14-27, 2016.

[107] Y. Y. Gong, L. Torres-Sanchez, L. Lopez-Carrillo et al., "Association between tortilla consumption and human urinary fumonisin B1 levels in a Mexican population," Cancer Epidemiology Biomarkers \& Prevention, vol. 17, no. 3, pp. 688-694, 2008.

[108] P. C. Turner, V. J. Burley, J. A. Rothwell, K. L. M. White, J. E. Cade, and C. P. Wild, "Dietary wheat reduction decreases the level of urinary deoxynivalenol in UK adults," Journal of Exposure Science \& Environmental Epidemiology, vol. 18, no. 4, pp. 392-399, 2008.

[109] New Vision, Uganda's Re-energized Campaigns against AFs, November 2018, http://www.newvision.co.ug/new_vision/ news/1488795/ugandas-energized-campaign-aflatoxins.

[110] U.S. Government supports launch of campaign to combat toxins in agricultural produce, November 2018, http://www. usaid.gov/uganda/press-releases/nov-1-2018-us-governmentsupports-launch-campaign-combat-toxins.

[111] Uganda Launches Aflatoxin Campaign, http://www. accessagriculture.org/uganda-launches-aflatoxin-campaign.

[112] New Vision, Maize Exporters Tipped on Standards, October 2015, http://googleweblight.com/i?u=https://www.newvision. co.ug/new_vision/news/1411115/maize-exporters-tippedstandards\&hl=en-UG.

[113] Stronger, EAGC, http://eagc.org/wp-content/uploads/2018/ 01/EAGC_@10_Milestone.pdf.

[114] R. L. Brown, D. Bhatnagar, T. E. Cleveland, Z. Chen, and A. Menkir, "Development of maize host resistance to aflatoxigenic fungi," in Aflatoxins: Recent Advances and Future Prospects, M. R. Mehdi, Ed., InTech, Rijeka, Croatia, 2013.

[115] K. Hell, P. Fandohan, R. Bandyopadhyay et al., "Pre- and post-harvest management of Aflatoxin in maize," in Mycotoxins: Detection Methods, Management, Public Health and 
Agricultural Trade, J. F. Leslie, R. Bandyopadhyay, and A. Visconti, Eds., CABI Publishing, Wallingford, UK, 2008.

[116] T. B. Whitaker, "Detecting mycotoxins in agricultural commodities," Molecular Biotechnology, vol. 23, no. 1, pp. 61-72, 2003.

[117] P. Fandohan, D. Zoumenou, D. J. Hounhouigan, W. F. O. Marasas, M. J. Wingfield, and K. Hell, "Fate of aflatoxins and fumonisins during the processing of maize into food products in Benin," International Journal of Food Microbiology, vol. 98, no. 3, pp. 249-259, 2005.

[118] D. L. Park, "Effect of processing on aflatoxin," in Mycotoxins and Food Safety. Advances in Experimental Medicine and Biology, J. W. DeVries and L. S. Jackson, Eds., vol. 504, Springer, Boston, MA, USA, 2002.

[119] P. Turner, A. Sylla, Y. Gong et al., "Reduction in exposure to carcinogenic aflatoxins by postharvest intervention measures in west Africa: a community-based intervention study," The Lancet, vol. 365, no. 9475, pp. 1950-1956, 2005.

[120] C. B. N'dede, C. M. Jolly, S. D. Vodouhe, and P. E. Jolly, "Economic Risks of AF Contamination in Marketing of Peanut in Benin," Economics Research International, vol. 2012, Article ID 230638, 12 pages, 2012.

[121] K. M. Glaston, M. Mvula, H. Koaze, and N. Baba, "Aflatoxin contamination of Kenyan maize flour and malted Kenyan and Malawian grains," Scientific Reports of the Faculty of Agriculture, vol. 89, pp. 5-7, Okayama University, Okayama, Japan, 2000.

[122] A. O. Makokha, R. Oniang'o, S. M. Njoroge, and O. K. Kamar, "Effect of traditional fermentation and malting on phytic acid and mineral availability from Sorghum bicolor and finger millet Eleucine caracana grain varieties grown in Kenya," Food and Nutritional Bulletin, vol. 23, no. 3_suppl 1, pp. 241-250, 2002.

[123] C. Mutungi, P. Lamuka, S. Arimi, J. Gathumbi, and C. Onyango, "The fate of aflatoxins during processing of maize into muthokoi-a traditional Kenyan food," Food Control, vol. 19, no. 7, pp. 714-721, 2008.

[124] G. Avantaggiato, F. Quaranta, E. Desiderio, and A. Visconti, "Fumonisin contamination of maize hybrids visibly damaged by Sesamia," Journal of the Science of Food and Agriculture, vol. 83, no. 1, pp. 13-18, 2003.

[125] G. P. Munkvold, "Cultural and genetic approaches to managing mycotoxins in maize," Annual Review of Phytopathology, vol. 41, no. 1, pp. 99-116, 2003.

[126] T. Omara, K. F. Kateeba, B. Musau et al., "Bioinsecticidal activity of eucalyptol and 1R-alpha-pinene rich acetonic oils of Eucalyptus saligna on Sitophilus zeamais Motschulsky, 1855 (Coleoptera: Curculionidae)," Journal of Health and Environmental Research, vol. 4, no. 4, pp. 153-160, 2018.

[127] S. A. Bankole, "Effect of essential oils from two Nigerian medicinal plants (Azadirachta indica and Morinda lucida) on growth and aflatoxin B 1 production in maize grain by a toxigenic Aspergillus flavus," Letters in Applied Microbiology, vol. 24, no. 3, pp. 190-192, 1997.

[128] G. O. Adegoke, H. Iwahashi, Y. Komatsu, K. Obuchi, and Y. Iwahashi, "Inhibition of food spoilage yeasts and aflatoxigenic moulds by monoterpenes of the spice Aframomum danielli," Flavour and Fragrance Journal, vol. 15, no. 3, pp. 147-150, 2000.

[129] P. J. Cotty and K. F. Cardwell, "Divergence of West African and North American communities of Aspergillus section Flavi," Applied and Environmental Microbiology, vol. 65, no. 5, pp. 2264-2266, 1999.
[130] H. K. Abbas, C. Accinelli, and W. T. Shier, "Biological control of aflatoxin contamination in U.S. crops and the use of bioplastic formulations of Aspergillus flavus biocontrol strains to optimize application strategies," Journal of Agricultural and Food Chemistry, vol. 65, no. 33, pp. 7081-7087, 2017.

[131] P. Villers, "Aflatoxins and safe storage," Frontiers in Microbiology, vol. 5, no. 158, pp. 1-6, 2014.

[132] P. E. Sumner and D. Lee, Reducing Aflatoxin in Corn during Harvest and Storage, The University of Georgia, Georgia College of Agriculture and Environmental Sciences, Atlanta, GA, USA, 2012.

[133] B. Kabak and A. D. W. Dobson, "Biological strategies to counteract the effects of mycotoxins," Journal of Food Protection, vol. 72, no. 9, pp. 2006-2016, 2009.

[134] G. Ramesh, Symptoms, Diagnosis, and Pathophysiology of Mycotoxin Exposure, Murray State University, Murray, Kentucky, 2012. 


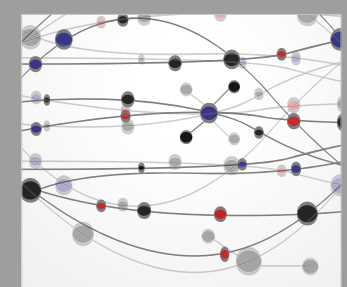

The Scientific World Journal
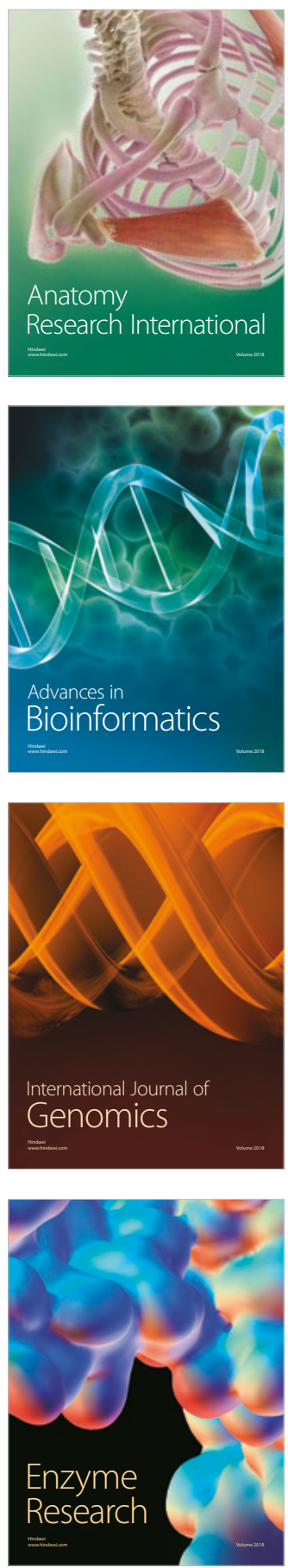
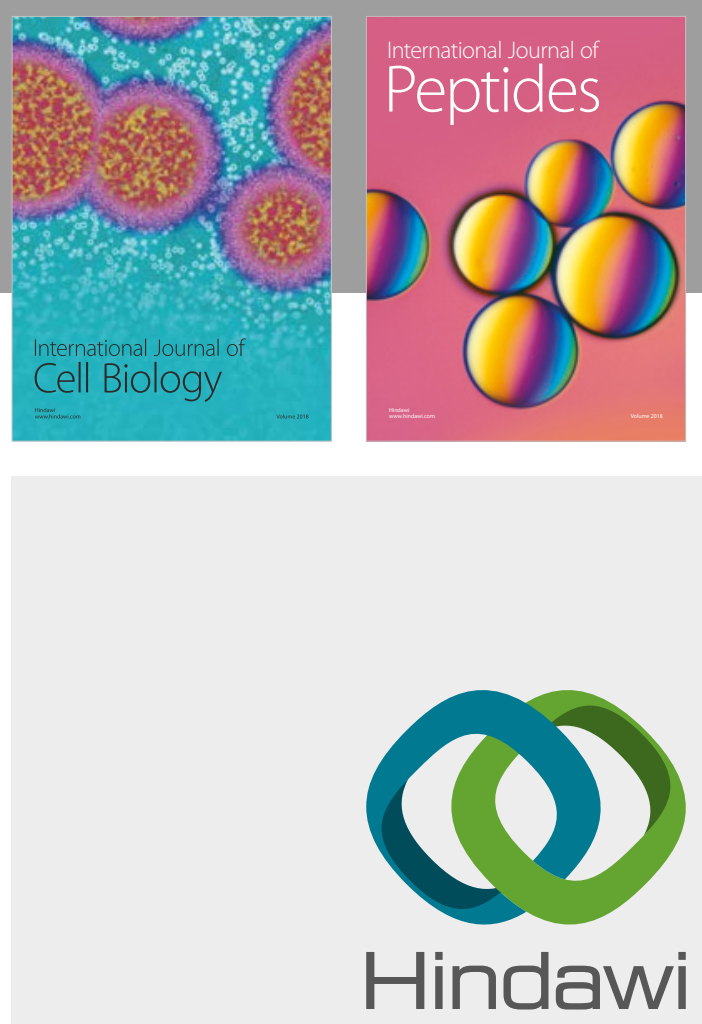

Submit your manuscripts at

www.hindawi.com
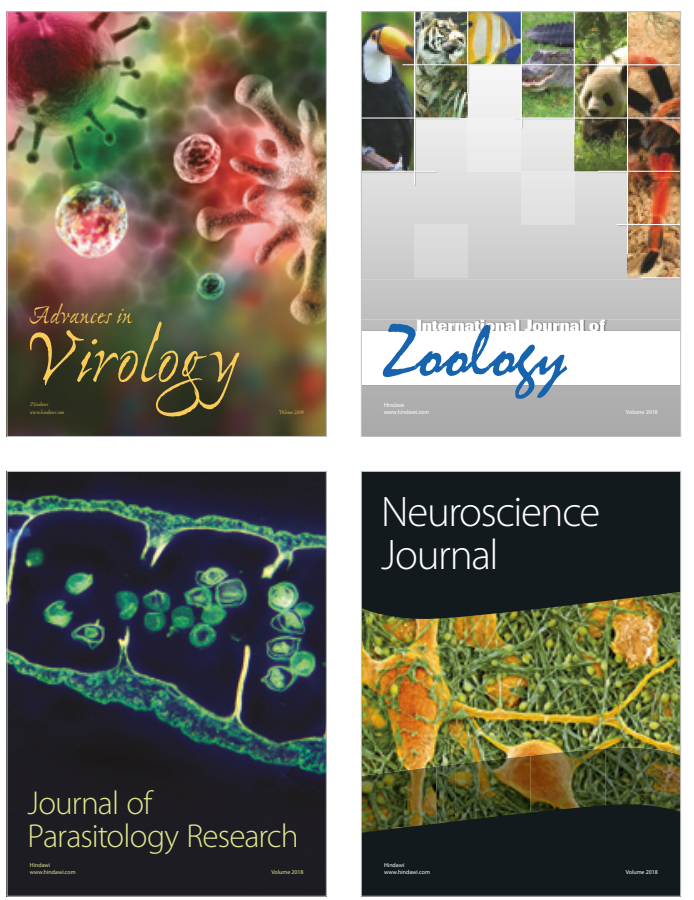
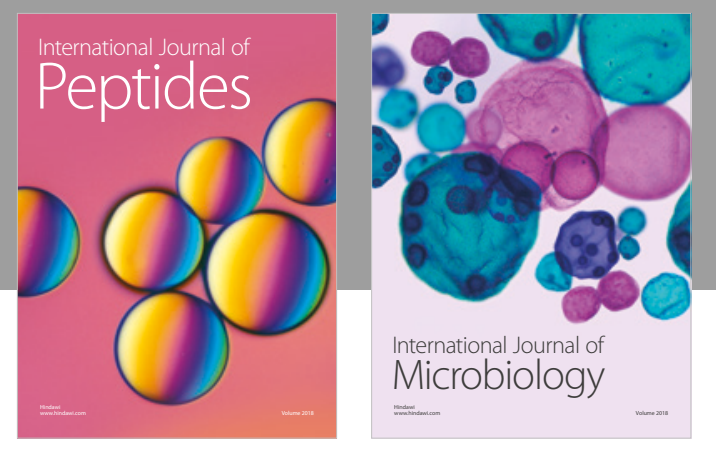

nternational Journal of Microbiology
Journal of
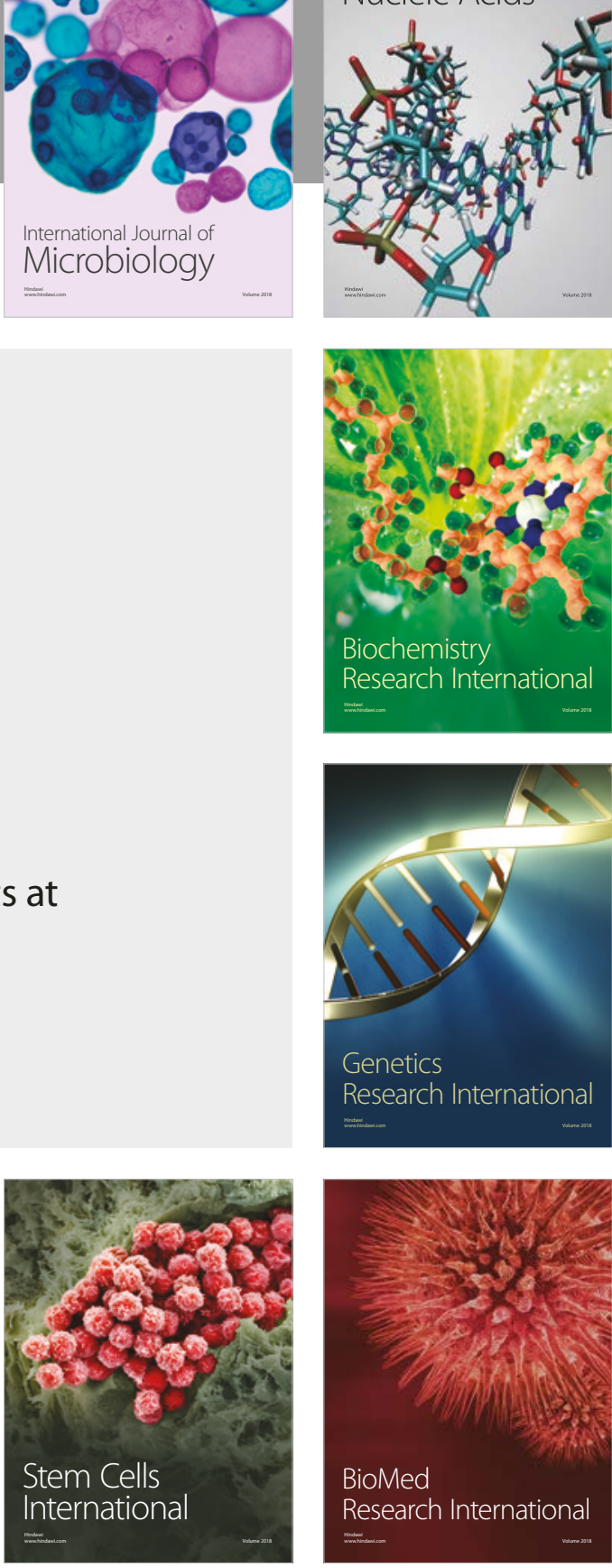
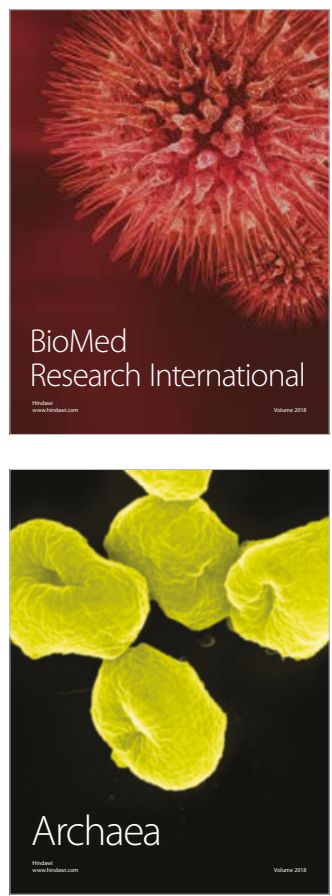